\title{
Alimentos de origen animal y enfermedades de transmisión alimentaria en Costa Rica: 2015-2020
}

\author{
Andrés Cartín-Rojas $^{1,2,3}\left[\right.$, Alina Pascual Barrera ${ }^{4}[D$ \\ 1. Universidad Estatal a Distancia, Escuela de Ciencias Exactas y Naturales (ECEN), Carrera de Ingeniería Agronómica, \\ Cátedra de Ciencias Agropecuarias, San José, Costa Rica, acartin@outlook.com \\ 2. Universidad Técnica Nacional, Carrera de Medicina Veterinaria, Atenas Alajuela, Costa Rica. \\ 3. Universidad para la Cooperación Internacional, Facultad de Ciencias de la Salud, Maestría en Gerencias de Programas \\ Sanitarios en Inocuidad Alimentaria, San José Costa Rica. \\ 4. Universidad Internacional Iberoamericana de México, Programa de Doctorado en Proyectos, Campeche, México; \\ alina.pascual@unini.edu.mx
}

Recibido 10-VI-2021 • Corregido 2-IX-2021• Aceptado 28-IX-2021

DOI: https://doi.org/10.22458/urj.v13i2.3587

\begin{abstract}
Food of animal origin and foodborne diseases in Costa Rica: 2015-2020". Introduction: Foodborne Diseases (commonly known by the acronym of ETAs), significantly impact the health systems of countries. Objective: Perform a thematic search that identifies the main biological hazards that cause ETAs described in Costa Rica and relate the main foods of animal origin with which they are linked. Methodology: A search for scientific information was carried out under the modality of literary review of narrative and descriptive cohort, from June 2015 to December 2020. Only articles with description of one or more pathogenic organisms that were linked to food matrices of animal origin in Costa Rican territory were selected for this bibliographic review. Results: We identified 27 types of biological organisms associated with ETAs, isolated from different matrices of animal origin in Costa Rica. Conclusion: There is a plurality of organisms frequently associated with infections, toxoinfections and infestations in humans. With a growing panorama of increasing consumption of animal products to cope with population growth by 2050, these challenges are increasing in parallel. For this, it is imperative to implement the OneHealth concept in the productive schemes of the countries.
\end{abstract}

Keywords: Food safety, Foodborne zoonoses, OnHealth, Animal products, Zoonoses.
RESUMEN: Introducción: Las Enfermedades de Transmisión Alimentaria (conocidas comúnmente con el acrónimo de ETAs), impactan significativamente en los sistemas de salud de los países. Objetivo: Realizar una búsqueda temática que identifica los principales peligros de tipo biológico causantes de ETAs descritos en Costa Rica, y relacionar los principales alimentos de origen animal con los cuales se vinculan. Metodología: Realizamos una búsqueda de información científica bajo la modalidad de revisión literaria de cohorte narrativo y descriptivo, desde junio de 2015 hasta diciembre de 2020. Seleccionamos para la presente revisión bibliográfica, únicamente artículos con descripción de uno o varios organismos patógenos que estuvieran vinculados con matrices alimentarias de origen animal, en el territorio costarricense. Resultados: Identificamos 27 tipos de organismos biológicos asociados con cuadros de ETAs, aislados de distintas matrices de origen animal en Costa Rica. Conclusión: Existe una pluralidad de organismos frecuentemente asociados con infecciones, toxoinfecciones e infestaciones en el ser humano. Con un panorama creciente de incremento en el consumo de productos de origen animal para hacer frente al crecimiento poblacional al año 2050, estos retos se incrementan en paralelo. Para ello es imperativo la implementación del concepto Una Salud en los esquemas productivos de los países.

Palabras clave: Inocuidad alimentaria, zoonosis alimentarias, UnaSalud, Alimentos de Origen Animal, Zoonosis. 
Las Enfermedades de Transmisión Alimentaria (ETAs), impactan significativamente los sistemas de salud de los países. La Organización Mundial de la Salud (OMS) estima que anualmente ocurren aproximadamente 600000000 infecciones de ETAs (mayoritariamente en los países en vías en desarrollo). A consecuencia de ello, se registran 420000 muertes y 27000000 días perdidos a consecuencia de incapacidades y hospitalizaciones. En el caso específico de las Américas, el promedio de días perdidos es de 140 por cada 100000 habitantes (Lee, 2017). Asimismo, la diarrea causada principalmente por ETAs de tipo microbiológico y en especial de índole bacteriano, constituye una importante causa de decesos en poblaciones vulnerables de países en desarrollo, especialmente niños entre los 0-5 años y personas con cuadros de inmunosupresión (Odeyemi \& Sani, 2016).

Hoy en día persisten retos significativos que sortear para conseguir que los productos y subproductos alimenticios de origen animal (POA) que llegan a las mesas de los consumidores estén libres de riesgos o al menos estos presenten un nivel aceptable. Esto es particularmente cierto para los países en vías de desarrollo en donde muchas veces el sistema de gestión de inocuidad de alimentos debe ser mejorado. En muchos países en vías de desarrollo, las infecciones e intoxicaciones alimentarias son subestimadas y sub-reportadas, lo cual impacta negativamente las acciones que en estos países se ejecutan para disminuir su incidencia (Odeyemi, 2016). En consecuencia, existe una diversidad en los sistemas regulatorios y de monitoreo entre países que deben ser subsanados para hacer frente al creciente riesgo a la higiene de alimentos, bajo un contexto altamente cambiante producto de la globalización comercial. Es precisamente en este entorno de interconexión y fluidez comercial que resulta vital el lograr asegurar la idoneidad de los insumos pecuarios expendidos (Uyttendaele et al., 2016). Es importante señalar, que entre los factores que predisponen a la emergencia o re-emergencia de ETAs, alteran la exposición global a patógenos transmitidos por los alimentos, y contribuyen a la variabilidad en su nivel de riesgo, están: 1) Cambios en la forma de producción y fabricación de los alimentos, 2) Globalización de mercados y libre trasiego de mercancías, 3) Adaptación microbiana y evolución de patógenos, y 4) Modificaciones en el estilo de vida y hábitos de consumo.

Las ETAs son ocasionadas cuando un peligro alimentario se encuentra en la concentración o dosis infectante suficiente en el alimento, para generar un cuadro clínico cuando ese alimento es ingerido por el consumidor. A saber, existen tres tipos de peligros alimentarios:

1. Biológicos: son el tipo de peligro más importante y frecuente. Son causados por la presencia de hongos, virus, priones, parásitos o bacterias en los alimentos. En el caso de los organismos parasitarios se habla de infestaciones, mientras que para los demás agentes nosógenos se hace referencia a infecciones. También se incluyen las toxinas de origen bacteriano, metabolitos tóxicos de naturaleza micótica (referidos como micotoxicosis) o por toxinas marinas (referidas dependiendo de la matriz alimentaria que sirve como fuente de transmisión de la toxina, como ictiotoxicosis (asociada con peces) o bivalvotoxicosis (asociada por la ingesta de moluscos bivalvos esencialmente que poseen altas concentraciones de la toxina). De todos ellos, los más frecuentes son los microorganismos de tipo bacteriano que pueden generar dos tipos de ETAs. En primer lugar, están las infecciones, que ocurren cuando la enfermedad es causada en sí por el agente etiológico presente en el alimento que se ingiere. En contraste, se encuentran las toxoinfecciones, que son trastornos que ocurren a consecuencia de consumir un producto de origen animal conteniendo las toxinas de uno o más grupos bacterianos. Las bacterias representan cerca del $70 \%$ de organismos causantes de ETAs, seguidas en importancia por los virus y los parásitos en último lugar (Varela et al., 2016). 
2. Físicos: son ocasionados por la presencia de faneras (pelo, uñas, etc.), material orgánico (astillas, insectos, etc.) u objetos de origen metálicos (clavos, tuercas, alambre, etc.) que se encuentran presente en los alimentos. Estos últimos son los más importantes en término de impacto a la salud pública por la probabilidad de ruptura del Sistema Digestivo o por la generación de asfixia (Peña \& Nava, 2016).

3. Químicos: En este caso se habla de intoxicaciones. La presencia en los alimentos de estos compuestos puede inducir la potenciación de la patogenicidad de ciertos organismos etiológicos de interés médico o bien, generar la disrupción de distintos sistemas orgánicos. Entre ellos destacan: derivados del empaque del alimento, aditivos alimentarios, metales pesados, alérgenos, y los residuos de fármacos veterinarios o plaguicidas (Van Asselt et al., 2017).

En Costa Rica, si bien la tasa de infección por este tipo de microorganismos es relativamente baja (10.3/100.000 habitantes), el impacto de este tipo de enfermedades en el sistema de salud resulta significativo. Cálculos previos estiman el costo anual en más de \$31 millones, con un costo por cada caso individual que ronda los $\$ 224$. Esto representa aproximadamente el $0.06 \%$ del PIB nacional (Kopper et al., 2009).

Este artículo tiene como objetivo, realizar una búsqueda temática que identifica los principales peligros de tipo biológico causantes de ETAs descritos en Costa Rica, y relacionar los principales POA con los cuales se vinculan.

\section{METODOLOGÍA}

Se realizó una búsqueda de información científica bajo la modalidad de revisión literaria (Grant et al., 2009) de cohorte narrativo y descriptivo (Xiao \& Watson, 2019), empleando para ello la plataforma de Google Académico, en donde se incluyeron los siguientes parámetros de búsqueda (descriptores): 1) nombre del agente etiológico causante de la enfermedad, 2) matrices de productos de origen animal en que este puede encontrarse (por ejemplo: lácteos, cárnicos, miel, pescado, mariscos o embutidos), 3) la frase Costa Rica para poder enfocar la búsqueda a nivel local, 4) el término Enfermedades de Transmisión Alimentaria (ETAs), y 5) la frase inocuidad alimentaria. La búsqueda de artículos se realizó desde junio de 2015 hasta diciembre de 2020. Se seleccionaron para la presente revisión bibliográfica, únicamente artículos con descripción de uno o varios organismos patógenos que estuvieran vinculados con matrices alimentarias de origen animal, en el territorio costarricense.

\section{RESULTADOS}

La búsqueda generó un total de 6290 resultados, de los cuales solo 72 fueron utilizados en el presente estudio. Se identificaron 27 tipos de microorganismos vinculados a ETAS y asociados a uno o más productos de origen animal. De ellos, 3,7\% correspondió a un agente micótico, 7,4\% a organismos de tipo viral, $22,2 \%$ a parásitos, $51,8 \%$ a bacterias, $11,1 \%$ a trastornos asociados con bivalvotoxicosis y $3,7 \%$ a fitotoxicosis. A continuación, se detalla más sobre los tipos de organismos identificados y los POA con los cuales se vinculan. 


\section{Organismos fúngicos}

El principal impacto de importancia para la salud humana deriva de la presencia de metabolitos tóxicos (conocidos como micotoxinas), que son producidos por ciertos hongos filamentosos. Los animales adquieren estos metabolitos tóxicos a partir del alimento (concentrado o ensilaje), el cual ha sido almacenado en condiciones inadecuadas de temperatura y humedad, o bien; porque la materia prima con la cual se fabrica el alimento (granos generalmente) está contaminado. Existe una susceptibilidad por especie en la patogenicidad y el nivel de toxicidad a consecuencia de las micotoxinas (Granados-Chinchilla, 2017). Algunos de estos metabolitos pueden llegar a los POA en concentraciones suficientes para generar un impacto importante en la salud de los consumidores.

En Costa Rica, los límites máximos (LM) permitidos de micotoxinas en materias primas destinadas a la elaboración de alimento para animales, están reguladas bajo los Decretos Ejecutivos $27980-S$ y $27964-S$. El monitoreo y diagnóstico certero para la identificación y cuantificación de este tipo de metabolitos tóxicos en materias primas destinadas a la alimentación animal, resulta vital en la prevención contra este tipo de toxinas. Esto es de esencial importancia para Costa Rica en donde la mayoría del maíz destinado a la nutrición animal se importa. La presencia de micotoxinas por encima de LM en los alimentos de origen animal demuestra la existencia de malas prácticas de gestión sanitaria en la manipulación, proceso, transformación, almacenamiento y distribución de los insumos de origen animal involucrados, así como las materias primas necesarias en la manufactura de algunos de ellos, y en los concentrados destinados a la alimentación animal. En nuestro país, el único reporte existente sobre la presencia de micotoxinas en POA está dado por la presencia de Aflatoxina (metabolito tipo $\mathrm{M}_{1}$ ) en leche y queso (Alvarado \& Granados, 2015; Molina et al., 2019).

\section{Organismos virales}

El contagio por este tipo de microorganismos se da generalmente por la ingesta de alimentos contaminados con el virus. Los brotes de enfermedades virales trasmitidas por alimentos frecuentemente se atribuyen a la higiene personal deficiente o provisión de agua contaminada. Dentro de los virus de importancia en POA, se haya el virus de la Hepatitis E, y recientemente la Leucosis Bovina catalogada como un potencial agente zoonótico.

En el caso de la Hepatitis E, la patogénesis de la Hepatitis E (HEV) en el ser humano es poco entendida, pero se sospecha de una reacción inmunomediada y de carácter autoinmune hacia los hepatocitos. La respuesta del organismo es esencialmente humoral, debido a los altos niveles de inmunoglobulinas (IgM e IgG) circundantes durante la infección. Se estima que la seroprevalencia del virus en la población latinoamericana es de un $6 \%$ de ella (Fierro et al., 2016). El contagio con este virus se asocia con el consumo de carne de cerdo cruda o incorrectamente cocida.

En el Costa Rica, se reporta el aislamiento e identificación del virus de la Hepatitis E en porquerizas del Valle Central y mencionan la circulación de este en la población humana, sin manifestaciones clínicas significativas producto de la hepatitis aguda autolimitantes que este virus genera (Kase et al., 2008). En el caso particular del Virus de la Leucosis Bovina (VLB), este agente etiológico ha llamado la atención de la comunidad científica internacional en años recientes, debido a que cada día más se le considera como un microorganismo con potencial zoonótico. El VLB tiene propiedades mamotrópicas, por lo que se concentra en altas cantidades en el tejido mamario. Estudios previos han detectado la presencia de porciones de genoma del virus en tejido humano mamario con procesos neoplásicos malignos, de ahí su asociación como potencial agente zoonótico (Buehring et al., 2015, Buehring et al., 2017).

La presencia del virus ha sido detectada en leche no pasteurizada y carne cruda, por lo que la transmisión alimentaria es una posibilidad (Olaya- Galan et al., 2017). El control mediante la 
cocción industrial de la leche (pasteurización), inhibe el potencial replicativo y virulencia del virus. Estos datos son de relevancia para Costa Rica, ya que el virus de la Leucosis Bovina se encuentra ampliamente distribuido en el territorio nacional, con una incidencia en hatos lecheros de hasta un 97\% (Romero et al., 2015).

\section{Organismos parasitarios}

Los heterópodos son tremátodos que pueden ser transmitidos al ser humano al consumir su tejido muscular crudo o inadecuadamente cocido de los reservorios del parásito (Carrique-Mas \& Bryant, 2013). Una de las especies más importantes por su rol zoonótico es Cestrocestus formosanus. Este parasito fue introducido en el continente americano en la década de 1950. Posee un complejo ciclo de vida que incluye tanto moluscos como peces teleósticos como huéspedes intermedios (Ximenes et al., 2017). El hecho de que culturalmente el pescado crudo se ingiera ampliamente en forma de platillos tradicionales como el ceviche, presenta un riesgo latente para la presencia de futuros casos clínicos en la región americana (Pulido-Murillo et al., 2018).

En Costa Rica, el gastrópodo Melania tuberculata (que se encuentra ampliamente distribuido) es considerado el hospedador intermedio de Centrocestus formosanus y $O$. niloticus como su hospedador definitivo. El ser humano es un huésped accidental. Su reporte en tilapia se registra localizado a la zona de Guanacaste (Arguedas et al., 2010; Arguedas et al., 2017).

Las infecciones en el ser humano causadas por nematodos de la Familia Anisakidae, se denominan Anasakosis. Entre los múltiples géneros de parásitos que generan esta patología, se haya el género Contracaecum spp. El hombre es un hospedador accidental e ingiere el parásito al consumir productos crudos o mal cocidos de las especies que son sus hospedadores intermedios (peces o crustáceos) (Serrano-Martínez et al., 2017).

La infección es de curso subagudo y la sintomatología clínica se caracteriza por dolor abdominal, náuseas, vómito, irritación intestinal y diarrea. En Costa Rica se reporta el hallazgo de Contracaecum spp., en especies locales de la ictiofauna dulceacuícola. Si bien el consumo de peces de rio crudos no es común, estos hallazgos muestran un eventual riesgo a la salud pública producto del consumo crudo o mal cocido de ellas y la existencia de un ciclo selvático del parásito. Por medio de análisis moleculares se identifica la presencia de $C$. multipapillatum en el territorio costarricense (Choc et al., 2020).

En América Latina, África y Asia existen unos 23 millones de personas infectadas con el trematodo Paragonimus spp, en donde la enfermedad es endémica. Las especies zoonóticas relevantes en el continente americano son $P$. mexicanus, $P$. caliensis y $P$. kellicotti (Culquichicón et al., 2017). El contagio ocurre por el consumo de carne cruda o insuficientemente cocida de crustáceos decápodos dulceacuícolas (cangrejos, langostinos, etc.), que contienen el estado infectivo del parásito (la metacercaria). La Paragonomiasis es una ETAs subdiagnosticada debido a que el parásito se aloja en el pulmón, por lo que su sintomatología suele confundirse con afecciones crónicas relacionadas al sistema respiratorio como la Tuberculosis o la Neoplasia Pulmonar (Fischer $\&$ Weil, 2015).

En Costa Rica, el caracol Aroapyrgus costaricensis es el primer hospedador intermediario, mientras que los cangrejos (Ptychophallus tristani y Pseudothelphusa magna) son los huéspedes intermedios de segundo nivel (Brenes et al., 1984). Su prevalencia localmente es baja y muchos aspectos epidemiológicos de la enfermedad son aún desconocidos (Ulate et al., 2015). Actualmente se reconocen a las especies $P$. mexicanus, y $P$. caliensis presentes en Costa Rica (Hernández-Chea et al., 2016).

Entre las especies infectantes de céstodos para el ser humano se encuentra Echinococcus granulosus, Taenia saginata que afecta bovinos o $T$. solium que infecta porcinos. E. granulosus es un parásito que es adquirido por los ungulados a través del consumo de pasto contaminado con las 
heces del hospedador definitivo, que son cánidos silvestres o domésticos. El consumo de carne de los huéspedes intermediarios o productos cárneos mal cocidos constituye la principal ruta de infección para el ser humano. Este cestodo causa la formación de quistes en distintos tejidos (hígado, pulmón, cerebro, etc.) de los animales afectados, incluido el ser humano en donde la enfermedad recibe el nombre de Hidatosis (Manterola et al., 2016). En Costa Rica no existen reportes de casos en humanos por E. granulosus. Sin embargo, se reporta su presencia en el pulmón de bovino, lo cual indica la presencia de este microorganismo en el territorio costarricense de forma muy infrecuente.

La presencia de Taenia saginata y $T$. solium respectivamente, ha sido reportada previamente en el territorio nacional (Rodríguez-Ortíz et al., 2004). La prevalencia de Cysticercus bovis en canales decomisadas de plantas de faenamiento animal en Costa Rica, es relativamente baja $(0,3 \%)$, lo que hace pensar que en paralelo la prevalencia en seres humanos es baja (López, 2017). Sin embargo, la prevalencia real por infecciones parasitarias asociadas a cestodos del género Taenia spp., en seres humanos en Costa Rica no se conoce realmente (Solano-Barquero \& LeónAlán, 2018).

La Toxoplasmosis es una de las enfermedades parasitarias con mayor prevalencia en el ser humano en el mundo. En Costa Rica, su agente causal Toxoplasma gondii, muestra como principal vía de trasmisión la ingesta de carne y embutidos inadecuadamente cocidos (Reyes-Lizano et al. 2001). Si bien aún es posible detectar insumos cárneos contaminados, su prevalencia en estos productos ha disminuido considerablemente durante los últimos años (Varela-Villalobos et al., 2013).

\section{Organismos bacterianos}

Las bacterias del género Aeromonas spp., son organismos bacilares, Gram negativos, móviles y anaerobios facultativos. Las especies mesófilas más importantes son $A$. hydrophila, $A$. sobria y $A$. caviae siendo asociadas con brotes de gastroenteritis en seres humanos. Existen también organismos psicrófilos como $A$. salmonicida. Este género bacteriano, posee una resistencia intrínseca a las drogas antimicrobianas de tipo betalactámico. Es considerada como el principal agente biológico que afecta la vida útil de pescados de agua dulce y posee importancia en la salud pública por su capacidad de generar toxoinfecciones. En Costa Rica, se reportan su presencia en tilapia (Morales et al., 2004). También la presencia de A. hydrophila, A. sobria, y A. caviae en moluscos bivalvos cultivados (Rodríguez \& Antillón, 1989).

Arcobacter spp., es un género de bacterias Gram negativas, aerotolerantes, de forma bacilar y móviles por flagelos polares simples (anfítricos). Las especies de Arcobacter spp., con importancia en veterinaria y salud pública, son: $A$. butzleri, $A$. cryaerophilus, y A. skirrowii.

Arcobacter spp., ha sido aislada a partir de distintas matrices cárnicas. Sin embargo, es mayor su prevalencia en insumos provenientes de carne de pollo, y en menor medida en productos lácteos no pasteurizados, carne de cerdo e insumos pesqueros.

Este microorganismo ha sido aislado previamente en Costa Rica con prevalencias de $48 \%$ para la carne bovina (Córdoba-Calderón et al., 2017). La prevalencia global de este patógeno en la cadena avícola costarricense es de 6,5\%, y la prevalencia específica según cada producto implicado es de: vísceras (17\%) y pechuga de pollo (56\%). Su prevalencia más alta se encontró en puestos de venta directa al consumidor, demostrando la existencia de un riesgo potencial a la salud de los consumidores (Barboza et al., 2017a). También se describe su presencia en muestras en distintos niveles, en la agrocadena avícola costarricense (Bogantes et al., 2015). Las especies aisladas encontradas fueron: $A$. thereius, $A$. butzleri, $A$. skirrowii y $A$. cibarius. En el caso de $A$. cryaerophilus esta se muestra, generando cuadros clínicos en personas en Costa Rica (Barboza et al., 2017b). 
Bacillus cereus es un organismo Gram positivo formador de endosporas, aerobio facultativo, móvil por la presencia de flagelos distribuidos en la superficie celular y de morfología bacilar. Es también, un importante agente etiológico de toxoinfecciones en seres humanos. Su presencia en Costa Rica se ubica dentro de la agrocadena de lácteos, y específicamente en diversos tipos de quesos (Blanco et al., 2009), leches deshidratadas (Rojas et al., 2014), arroz con leche (un platillo típico costarricense) (Carranza et al., 2013) y sushi (Madrigal et al., 2013).

Las bacterias pertenecientes al género Campilobacter spp., son organismos bacilares Gram negativos, microaerofílicos y móviles mediante flagelos polares, que causan la enfermedad conocida como Campylobacterosis, que es una de las ETAs más frecuentemente reportadas (Frasao et al., 2017). Los principales serovares aislados son $C$. jejuni y C. coli. Son organismos comensales y parte de la microbiota natural del tracto digestivo de gran variedad de animales, siendo los principales reservorios los cerdos para $C$. coli y las aves de corral para $C$. jejuni (siendo considerada esta la variante más patogénica para el ser humano).

La principal vía de infección para el ser humano lo constituye la ingestión de alimento contaminado con heces de animales portadores, por contaminación cruzada o mala manipulación de este durante su proceso de elaboración o la ingesta de carne mal cocida con una dosis infectante significativa (MacRitchie et al., 2014). En Costa Rica la presencia de esta bacteria se encuentra ampliamente distribuida en distintos eslabones de la cadena avícola y en los productos derivados de ella (Florin \& Antillón 1992, Rojas et al., 1996, Zumbado et al., 2014) Se menciona tanto la presencia de $C$. jejuni como de $C$. coli (Zumbado et al., 2019).

Coxiella burnetii es un bacilo gran negativo que frecuentemente se confunde con diversos agentes ricketsiales. Es causante la de enfermedad conocida como Fiebre $Q$, la cual pueden adquirir los seres humanos por el consumo de leche no pasteurizada y sus productos. No se reporta la presencia del microorganismo en matrices alimentarias de origen animal. Sin embargo, en el caso de Costa Rica, se reporta una prevalencia superior al 7\% para este organismo, en hatos caprinos lecheros (Villagra-Blanco et al., 2018).

Clostridium spp., es un género bacteriano bacilar, anaerobios, formadores de endosporas móviles y Gram positivos. Habitan mayoritariamente en zonas de termoconfort mesófilas, pero algunas cepas son psicotrófilas. Producen potentes toxinas biológicas, por lo que su importancia radica en la toxoinfección a nivel alimentaria que las mismas ocasionan. Son ubicuas, por lo que se distribuyen ampliamente en el ambiente y en distintos tipos de alimentos. Las especies de Clostridium spp., de importancia en inocuidad alimentaria y salud pública son tres: $C$. botulinum (asociada a productos enlatados), C. difficile (asociada a mariscos y carnes), y C. perfringens (asociada a carnes y embutidos).

En el caso de $C$. botulinum, existen al menos cuatro grupos que aglomeran todas las cepas de Clostridium botulinum hasta el momento conocidas (Peck \& van Vliet, 2016). De ellos, sólo los grupos I (organismos proteolíticos, mesófilos) y II (organismos no proteolíticos, psicotrópicos) tienen importancia en salud pública e inocuidad de alimentos. Las toxinas clases A, B, E y F se asocian con intoxicaciones de tipo alimentario. Clostridium perfringens posee dos toxotipos con propiedades citotóxicas. En primer lugar, una fosfolipasa C (toxina A) causante de infecciones e intoxicaciones de origen alimentario y asociado a casos de desórdenes gastrointestinales de tipo diarreico asociado con antibióticos. Por otro lado, se haya la toxina C causante de la enteritis necrótica (Uzal et al., 2014). C. difficile por su parte es catalogado como un patógeno emergente en alimentos, ya que la mayoría de los casos reportados, son debido a su rol como organismo nosocomial (Thitaram et al., 2016).

En Costa Rica, se reporta la presencia de Clostridium perfringens productor de toxina A en la pierna de cerdo, carnes de res (procesadas y molidas) y embutidos (Bolaños-Acuña et al., 2007). Asimismo, se describe el aislamiento y genotipificación de cepas de Clostridium difficile en muestra 
de cortes de carne listas para el consumo, y la presencia de este microorganismo como una importante causa de infecciones nosocomiales (Quesada-Gómez, 2013).

Las bacterias del género Enterococcus spp., son empleados en la industria láctea para la maduración de quesos y en la industria cárnica para la fermentación de embutidos. También son organismos indicadores de la calidad higiénica de los alimentos. Estos patógenos oportunistas se colocan entre los principales agentes patológicos de infecciones intrahospitalarias a nivel mundial. Las principales especies de importancia son E. faecium y E. faecalis. Su principal importancia radica, en que este grupo bacteriano posee una amplia versatilidad y plasticidad para transmitir e intercambiar de forma horizontal factores de virulencia y genes de resistencia.

La contaminación de los productos cárnicos se da por contaminación cruzada con materia fecal durante el sacrificio o despiece el animal. En el caso de insumos lácteos la contaminación de la leche y en el ambiente de lecherías, parece ser la causa de que esta bacteria incremente su carga durante los procesos de fabricación y maduración de diversos tipos de quesos. En Costa Rica, la prevalencia de Enteroccocus spp., en muestras de leche del área metropolitana fue de $71 \%$ para $E$. faecalis y $19 \%$ para E. faecium (Araya et al., 2005). Asimismo, este microorganismo está reportado en el territorio costarricense en piezas de pollo (Fernández, 2002) y tilapia fresca (Morales et al., 2004).

Las bacterias del género Escherichia spp., son bacterias anaerobias facultativas, comensales del tracto digestivo de una amplia variedad de mamíferos, Gram negativas, bacilos móviles por la presencia de flagelos perítricos. Existen seis grandes grupos importantes que generan enfermedad en el ser humano. De todas ella la más importante para la industria alimentaria debido a su alto nivel de virulencia, y por utilizar POA contaminados como fuentes de infección, en el subgrupo enterohemorrágica o verotoxigénica (Farrokh et al., 2013).

La mayoría de las cepas generan cuadros de gastroenteritis. Sin embargo, las cepas de Escherichia coli verotoxigenica (en especial la variante H7O157) son causantes del Síndrome Urémico Hemolítico (SUH), en el cual se genera un fallo agudo de los riñones que ocurre 1-2 semanas posteriores a un cuadro diarreico (Agger et al., 2015). El mismo es ocasionado por la liberación de verotoxinas, de la cual existen dos tipos (VTE1 y VTE2), también denominadas toxinas Shiga por su similitud estructural con las toxinas de Shigella dysenteriae. La principal verotoxina involucrada en casos de SUH, es la variante Stx2 y sus subtipos.

La transmisión vía alimentaria de la bacteria incluye el consumo de productos cárnicos de res, cerdo o pollo mal cocidos (principal ruta de contagio al ser humano), insumos lácteos no pasteurizados, o la ingesta de productos listos para el consumo infectados posterior a su manufactura. El riesgo de contaminación cruzada del producto ocurre en etapas como el deshuesado y los puntos de ventas al por mayor. Los rumiantes en menor medida que los cerdos, son portadores de cepas verotoxigénicas de toxina Shiga (Colello et al., 2016).

A nivel de los distintos tipos de agrocadenas alimentarias costarricenses, Escherichia coli 0157:H7 se describe en hígado de pollo y leche cruda de vaca (Reuben et al., 2003). La presencia de esta bacteria también ha sido descrita en diversas especies de pescados (Marín et al., 2009) y camarón (Arias \& Chaves 2012), tortas de carne, helados caseros (Arias \& Antillón, 2000), sushi (Madrigal et al., 2013), salchichón y carne molida (Monge \& Arias, 1991). Se reporta una prevalencia de 3,6\% para cepas de la variante 0157:H7 en cortes de carne de res, expendidas en el mercado local costarricense (Chaves et al., 2015), con la presencia cuadros clínicos en niños por E. coli 0157:H7 por el consumo de tortas de hamburguesa contaminadas (Martínez \& Herrera, 1997).

Listeria monocytogenes es un bacilo Gram positivo, anaerobio facultativo y móvil por flagelos perítricos. Es un organismo psicrófilico capaz de crecer a temperaturas cercanas a los $4^{\circ} \mathrm{C}$. El organismo crece en una amplia variedad de $\mathrm{pH}(4-9)$, posee tolerancia a altos niveles de salinidad 
(cercanos al 10\%) y formador de biofilms, lo que permite su persistencia en el ambiente de planta de proceso y con ello el riesgo de contaminación cruzada.

Los trastornos asociados con la Listeriosis poseen poca morbilidad, pero alta mortalidad (oscilan entre el 20-30\% de las personas infectadas) (Ferreira et al., 2014). L. monocytogenes, causa anualmente alrededor del $4 \%$ de retiros de producto en el mercado a nivel mundial, generando un importante impacto al sector agroalimentario mundial (Jami et al., 2014). En Costa Rica Listeria monocytogenes se encuentra en el queso fresco artesanal (Arias et al., 2010), helados pasteurizados, leche cruda, pescado fresco y derivados de pollo congelado (Arias \& Antillón, 2000).

Las bacterias pertenecientes al género Mycobacterium spp., son organismos bacilares aerobios, no móviles, y Gram positivas. Existe una diversidad de especies dentro del género, por lo que suelen agruparse en complejos. Dentro del Complejo M. tuberculosis, sobresale como organismo patógeno para el ser humano y de transmisión alimentaria $M$. bovis agente etiológico primario de la Tuberculosis Bovina y genera cerca del $10 \%$ de los casos de tuberculosis en el ser humano. Por otra parte, se tiene el complejo M. avium, en donde se encuentra M. paratuberculosis que causa la enfermedad de John en bovino, y causa un síndrome de mala absorción crónico en el ser humano conocido como Enfermedad de Crohn.

En Costa Rica se estimó que 1095 toneladas de carne contaminada con tuberculosis bovina y 192 toneladas de carne con lesiones fueron aprobadas como aptas para consumo humano entre los años 2003 y 2006 (Calvo-Artavia, 2008).

Otro organismo bacteriano de importancia en industria piscícola y con relevancia también en la industria alimentaria, lo constituye Plesiomonas shigelloides.

Este microorganismo es un bacilo Gram negativo, anaerobio facultativo, móvil. Esta bacteria es un organismo asociado a ambientes acuáticos, siendo común su hallazgo en moluscos bivalvos, peces y crustáceos tanto de agua salado como dulceacuícolas. Posee una distribución mundial. Aunque es considerada una ETAs asociado al consumo de insumos pesqueros mal cocidos o crudos, su incidencia en muy baja 1-2\%. Los mayores brotes de la enfermedad se reportan en Asia, aunque también hay reportados casos en Latinoamérica (Janda et al., 2016). Su presencia se reporta en el mercado ostrícola, específicamente en moluscos bivalvos cultivados del Golfo de Nicoya y destinados al consumo local (Rodríguez \& Antillón, 1989).

Los organismos pertenecientes al género Salmonella spp., son bacterias Gran negativos, de forma bacilar, anaerobios facultativos, mótiles por la presencia de flagelos perítricos y productora de biofilms que fomentan su persistencia en el ambiente. Existen realmente sólo tres especies bacterianas del género Salmonella spp., las cuales son: S. entérica, S. bongori y S. subterránea. A su vez S. entérica se divide en distintos serovares o subespecies (Fernández, 2014). Los agentes causantes de ETAS son los organismos tifoideos (causantes de la enfermedad conocida como Fiebre Tifoidea) que agrupan a los serovares Typhi y Paratyphi (Crump et al., 2015). La OMS estima que anualmente ocurren aproximadamente 78.7 millones de casos de ETAs en el mundo con 59000 muertes asociadas solo a este organismo (Chaabna \& Alali, 2017).

Se describe una prevalencia del $15 \%$ para menudos de pollo expendidos en el área metropolitana del país y positivos a Salmonella spp (Reuben et al., 2003), también se reporta en derivados de pollo congelados y huevo crudo (Arias \& Antillón, 2000). Asimismo, se estima una prevalencia de 4,7\% para cepas de Salmonella spp., en cortes de carne de res, expendidas en el mercado local costarricense (Chaves et al., 2015). Localmente, la contaminación microbiológica de la carne de pollo con esta bacteria, muestra ser una preocupación importante para los consumidores, que puede incluso llegar a alterar los patrones de compra y consumo de ciertos productos avícolas (Jaikel \& Ramírez, 2010).

Staphylococcus aureus es el principal patógeno representante de este género. Es una bacteria anaerobia facultativa, Gram positiva, redondeada, e inmóvil, es un organismo mesófilo 
comensal de la piel y patógeno oportunista que produce diversos tipos de enterotoxinas (Kadariya et al., 2014), por lo que causa toxoinfecciones autolimitantes (24-48 horas) que se caracteriza por: vómito, nausea, diarrea, dolor abdominal, perdida profusa de electrolitos y calambres musculares. Sus enterotoxinas son termoestables y además son potentes compuestos pirógenos (inducen fiebre). Son resistentes a bajos niveles de $\mathrm{pH}$ y a proteasas como tripsina y pepsina, lo que permite a la toxina resistir el proceso de digestión una vez que ha sido ingerida. Estas mismas características hacen que la toxina resista algunos tipos de procesos industriales diseñados a disminuir la carga bacteriana en los alimentos. De todas ellas, los subtipos Ay E son comúnmente aislados de brotes alimentarios (Mashouf et al., 2015). En Costa Rica Staphylococcus aureus es encontrado localmente en quesos frescos artesanales (Bolaños-Acuña et al., 2007), pescado (Marín et al., 2009), sushi (Madrigal et al., 2013), y almejas (Cortés \& Madriz, 1987), tortas de carne, salchichón y carne molida (Monge y Arias, 1991).

Los organismos pertenecientes al género Vibrio spp., son bacterias Gram negativas, de morfología bacilar, móviles por un único flagelo polar, y anaerobios facultativos. La Vibriosis es una importante enfermedad zoonótica que afecta al sector acuícola y pesquero. Las especies de microorganismos frecuentemente involucradas en ella son $V$. alginolyticus, $V$. harveyi, $V$. anguillarum, $V$. cholerae, $V$. parahaemolyticus, y $V$. vulnificus, siendo las tres últimas especies las que poseen mayor relevancia en salud pública (Amalina y Ina-Salwany 2016). La Vibriosis ocurre por la ingestión de agua o alimentos crudos y contaminados con bacterias del género Vibrio spp., entre los POA mayormente vinculados se encuentran: pescados, moluscos bivalvos (ostras) y crustáceos (camarón, cangrejos, etc.).

Vibrio spp., es una bacteria que puede comprometer seriamente la vida útil de los insumos pesqueros, los cuales aportan cerca del $0,75 \%$ del Producto Interno Bruto (PIB). Aparte de su impacto económico este organismo tiene importancia como agente causante de ETAS. En Costa Rica, para la barracuda (Sphyraena ensis) (una especie histaminoproductora) se reporta la presencia de $V$. alginolityicus (Álvarez et al., 2011). también V. parahaermolyticus para el camarón y la tilapia (Arias \& Chaves, 2012), y moluscos bivalvos causando importantes cuadros clínicos (Díaz \& Valerio, 2002). Se describe $V$. cholerae y $V$. mimicus en moluscos bivalvos procedentes del Golfo de Nicoya en el Pacífico costarricense (Antillón \& Rodríguez 1992).

El hallazgo de $V$. mimicus en el territorio costarricense, cobra importancia. El organismo se asocia al consumo de huevos frescos y crudo de tortuga marina (Lepidochelys olivacea). La contaminación in situ del producto en los puntos de anidación, requiere la destrucción o reducción del mismo sobre el alimento para minimizar su riesgo y prevenir futuros contagios. Por lo que se sugiere la aplicación de calor con temperaturas entre los $55-65^{\circ} \mathrm{C}$ por 20 minutos (pasteurización leve), como un método efectivo para la destrucción del inóculo sin afectar las características organolépticas del producto (Pereira-Zamora \& Wong-González, 2008).

Los integrantes del género Yersinia spp., son bacilos, Gram negativos, móviles por flagelos anfítricos y perítricos. Son tanto aerobios como anaerobios facultativos. Las especies de interés en inocuidad alimentaria son dos. En primer lugar, se encuentra $Y$. enterocolítica, entre sus características particulares está el ser un organismo psicrófilo que produce toxinas termoestables (a los $121^{\circ} \mathrm{C}$ por $30 \mathrm{~min}$ y a $-18^{\circ} \mathrm{C}$, junto a un bajo $\mathrm{pH}$ por varios meses), causa la enfermedad conocida como Yersiniosis (siendo esta la presentación más común de la enfermedad y caracterizándose por un cuadro gastroentérico). El serotipo 0:3 es el más comúnmente implicado en cuadros clínicos. Por otra parte, se tiene a Y. pseudotuberculosis, organismo vinculado también con el Síndrome de Izumi y la Enfermedad de Kawasaki.

Los principales reservorios del microorganismo son los cerdos (el organismo se concentra en sus tonsilas mayoritariamente). La principal fuente de infección, de ambos es el consumo de productos y subproductos elaborados a base de la carne de estos animales y que es ingerida cruda 
o con una cocción inadecuada (Bancerz-Kisiel \& Szweda, 2015). La literatura también menciona el consumo de leche y sus derivados no pasteurizados como otra forma sugerida para adquirir la infección, pero es menos frecuente (Tavares et al., 2017).

Hasta el momento, no se encuentra literatura científica que reporte Yersinia spp., en POA dentro del territorio costarricense. Sin embargo, si se menciona el hallazgo de $Y$. enterocolítica en casos de diarrea disentérica en niños y de abscesos mesentéricos, explicando que el microorganismo puede ser un agente etiológico subvalorado y presentar prevalencias mayores a las comúnmente reportadas, posiblemente por la semejanza del cuadro clínico mostrado con Shigella spp (Rodríguez et al., 2000). Por lo que constituye un importante organismo de evaluar y muestrear en diversas matrices de POA.

\section{Resistencia antibacteriana asociada a POA}

A nivel país el Servicio Nacional de Salud Animal (SENASA) es el ente rector en materia de sanidad animal. Este organismo, mantiene un activo Programa Nacional de Residuos que monitorea las concentraciones de fármacos veterinarios en los POA. Por tanto, el mayor problema en Costa Rica radica en la utilización de fármacos antimicrobianos en los sistemas primarios de producción, que generan presión selectiva sobre las poblaciones bacterianas que también pueden está presentes en los alimentos, y transmitir esta resistencia a la microbiota intestinal de las personas, predisponiendo la aparición de cuadros de ETAs de difícil tratamiento o incluso la generación de organismos intrahospitalarios resistentes.

En muchos países en desarrollo no existen normativamente guías o pautas a seguir para el uso de agentes antimicrobianos en especies productivas. Esto genera un sobreuso de estos. En Costa Rica, los controles existentes se han enfocado en regular la distribución y acceso a estos medicamentos. Actualmente en Costa Rica existen reglamentaciones para la producción avícola (Reglamento sobre Granjas Avícolas, Decreto Ejecutivo № 31088-S y sus reformas) y producción porcina (Reglamento sobre Granjas Porcinas, Decreto Ejecutivo $\left.N^{\circ} 37155-M A G\right)$ a nivel inicial de la agrocadena primaria, algo que no existe para la producción piscícola o bovina de leche o carne; dos de las áreas de producción animal donde existe un amplio y frecuente uso de agentes antimicrobianos.

En cuanto a resistencia antibacteriana se refiere, es importante indicar los hallazgos de organismos patógenos asociados con ETAs que presentan esta característica en el territorio costarricense. Se reporta la presencia de Tetraciclinas en lotes de alimentos destinado al consumo de distintas especies productivas (Gutiérrez et al., 2010). También se señala la presencia de importantes volúmenes de estos compuestos en ambientes acuáticos próximos a zonas con altas producciones acuícolas en la zona norte del país (De la Cruz et al., 2014).

Por otra parte, se reportan importantes porcentajes de resistencia antimicrobiana en cepas de Staphylococcus aureus, una bacteria que genera toxinas termoestables responsables de ocasionar cuadros de intoxicaciones alimentarias (Rodríguez et al., 2008). El consumo de leche por persona por año en Costa Rica es de $186.2 \mathrm{Kg}$, siendo uno de los datos más altos en América Latina (Pérez, 2015). Cerca del $40 \%$ de la producción láctea en el territorio costarricense, se destina al autoconsumo o se comercializa a través del sector artesanal informal. El biotipo metacilina resistente en cepas de $S$. aureus tuvo una prevalencia de $1.4 \%$ en el total de los quesos muestreados. Por otra parte, se describen también resistencias intrahospitalarias en Salmonella spp (Tijerino et al., 2016). De igual forma, la presencia de perfiles de resistencia a través de la producción de ßlactamasas (un mecanismo enzimático descrito ampliamente en compuestos betalactámicos como la Penicilina), en Escherichia coli, una importante bacteria zoonótica de transmisión alimentaria causante según su fenotipo, del Síndrome Urémico Hemorrágico (SUH) con subsecuente fallo renal, en un hospital del área capitalina de Costa Rica (Araya-Fonseca et al., 2007). 
El hallazgo de cepas nosocomiales de Enterococcus spp., (una bacteria lactógena) con resistencia a la vancomicina en el territorio costarricense reviste especial importancia (Salas-Vargas et al., 2004). Ya que además se describe la resistencia a este antibiótico en bacterias usados como probióticos en insumos lácteos en Costa Rica (Córdoba et al., 2009).

Estos hallazgos son trascendentales, ya que se encuentran perfiles similares de resistencia en este grupo bacteriano en heces de aves y porcinos en el territorio costarricense, sometidos a sistemas de producción intensiva y destinados al consumo humano local (Bustamante et al., 2003). Finalmente, se señala además la resistencia en cepas de $E$. faecalis y $E$. faecium en muestras de leche cruda para los siguientes antimicrobianos: estreptomicina, kanamicina, gentamicina. En menor medida se encuentra resistencia a la eritromicina, tetraciclina y cloranfenicol. Las cepas resistentes a vancomicina lo hicieron con una prevalencia del 8\% (Araya et al., 2005). El 75\% de las cepas encontradas para Enterococcus spp., en piezas de pollo, mostraron algún nivel de resistencia a la vancomicina (Fernández, 2002).

Existe un 52\% de prevalencia con cepas de Enteroccocus spp., del tipo VRE (resistentes a la vancomicina y teicoplanina), en los pacientes internados en las unidades de cuidado intensivo y emergencias médicas a los cuales se les realizaron hisopados rectales (Salas-Vargas et al., 2004). También se encuentran perfiles de resistencia en este grupo bacteriano en heces de aves y porcinos en el territorio costarricense, sometidos a sistemas de producción intensiva y destinados oplal consumo humano local (Bustamante et al., 2003).

Es importante señalar el aislamiento y hallazgo de importantes niveles de resistencia a fármacos de la familia de las Sulfas en cepas de Staphylococcus aureus, especialmente en quesos y también en aislamientos nosocomiales (Alvarado et al., 2011).

Clostidium perfringens, es un patógeno que se puede encontrar en embutidos. En Costa Rica, se menciona su resistencia al Metronizadol (Gamboa-Coronado et al., 2011), el cual es además un medicamento de importante uso antiparasitario.

La detección de la bacteria Aeromonas hydrophila (asociada en productos pesqueros), causando cuadros clínicos diarreicos en niños, en donde al menos la mitad de ellas corresponde a infecciones de tipo nosocomial. Las bacterias mostraron resistencia a la ampicilina, cefalotina, e imipenem (Herrera et al., 2000).

La presencia de cepas de Arcobacter spp., en la carne de res con perfiles de resistencia antimicrobiana a la ampicilina, levofloxacina, ácido nalidíxico y ciprofloxacina (Córdoba-Calderón et al., 2017); también se puntualiza la resistencia variable en variantes de esta bacteria aislada de la zona metropolitana de San José, a partir de menudos de pollo para el cloranfenicol, la ampicilina y la ciprofloxacina (Villalobos et al., 2013).

Un estudio realizado en cepas de Campylobacter spp., aisladas en Costa Rica de granjas avícolas, plantas de proceso de POA y puntos de ventas directas al público, evidenció perfiles con altos índices de resistencia a las quinolonas (mayor al 85\%) y en menor grado a las oxitetraciclinas (25\%) (Lazo, 2018).

Finalmente, se indica el hallazgo de cepas de Listeria monocytogenes en queso fresco reviste especial importancia, ya que las cepas aisladas en alimentos muestran importantes patrones de resistencia a diversos antibióticos como: estreptomicina, kanamicina, cefalotina y tetraciclina (Chaves \& Arias, 2009).

Por tanto, la presencia de fármacos veterinarios en los alimentos de origen animal posee, por tanto, relevancia en materia de salud pública y en ámbito comercial, ya que niveles no permitidos de los compuestos en los alimentos o los derivados de ellos, genera el rechazo del producto por parte de los socios comerciales y evidentes pérdidas económicas para el sector agroalimentario. 


\section{Toxinas marinas}

En los ambientes marino-costeros, las toxinas marinas son sustancias producidas por diversas especies de microalgas que conforman el fitoplancton (principalmente dinoflagelados y diatomeas), mientras que en ecosistemas dulceacuícolas las cianobacterias juegan un papel importante en su producción. Los gasterópodos (moluscos bivalvos) y actinopterigios (peces teleósteos) adquieren las toxinas al ingerirlos, en donde se bioacumulan. Posteriormente el ser humano se intoxica al ingerir los animales o partes de ellos que contienen los metabolitos tóxicos. Dentro este tipo de intoxicaciones, se agrupan dos tipos de ETAs según el alimento que sirve como vehículo para que la toxina llegue al consumidor final:

1. Bivalvotoxicosis: asociadas a la ingesta de gasterópodos contaminados con cierta variedad de metabolitos tóxicos, e

2. Ictiotoxicosis: asociadas al consumo de actinopterigios conteniendo cierta concentración de tipos específicos de toxinas marinas o compuestos alergénicos, producidos por la mala manipulación del producto.

Dentro del grupo de las bivalvotoxicosis, se describen cuatro tipos de intoxicaciones de importancia en salud pública:

1. Intoxicación paralitica por mariscos: ocasionada por las saxitoxinas y gonytoxinas. Estos compuestos modifican la permeabilidad de los canales de sodio, potasio y calcio lo cual altera el impulso nervioso y la contracción de la placa motora, generando la parálisis de los músculos respiratorios (Cusik \& Sayler 2013). Son producidas por dinoflagelados del fitoplancton en ambientes marinos (Leong et al., 2016) y por cianobacterias en ecosistemas dulceacuícolas (Suarez-Isla, 2015).

2. Intoxicación diarreica por mariscos: causada principalmente por el ácido okadaico y sus derivados tóxicos: dinofisistoxina (DTX), pectenotoxina (PTX) yesotoxina (YTX) y azaspiricida (AZA), generados por organismos dinoflagelados de los géneros Prorocentrum spp., y especialmente Dinophysis spp (Viscaino et al., 2016). La intoxicación aguda cursa por una sintomatología intestinal (diarrea, vómito, náuseas, dolor abdominal) y muscular (calambres). Sin embargo, los efectos crónicos de su consumo incluyen genotoxicidad, alteraciones de los sistemas inmune y nervioso, junto a una modificación del ADN celular, alteración de la actina en el citoesqueleto celular, y la fosforilación de los aminoácidos serina y treonina.

3. Intoxicación neurotóxica por mariscos: es causada por la ingestión de los metabolitos tóxicos de brevitoxinas, producida por el dinoflagelado causante de la marea roja (Karenia brevis) (Turner et al., 2015). Su patogénesis incluye sintomatología nerviosa, respiratoria y gastrointestinal. Las toxinas se unen a los canales de sodio citoplasmáticos ocasionando su despolarización (Viscaino et al., 2016).

4. Intoxicación amnésica por mariscos: causada por los productos de distintos grupos de diatomeas. Estos microorganismos producen el ácido domóico, un aminoácido cíclico tricarboxílico similar al ácido glutámico (receptor y neurotransmisor cerebral) (Doucette \& Tasker, 2008). Como consecuencia se sobre-estimulan los receptores de glutamato y se induce la formación de compuestos oxido-reductivos que llevan a la apoptosis celular, en áreas del 
hipocampo nervioso que es en donde se procesa el aprendizaje y la memoria (Morabito et al., 2017).

La mayoría de aislamientos de dinoflagelados tóxicos han sido es aguas de mar de distintos puntos geográficos de la costa pacífica de Costa Rica (Freer \& Vargas-Montero, 2003), y se indica la existencia en aguas territoriales de organismos capaces de producir yessotoxinas, saxitoxinas, y ácido domóico. Sin embargo, en materia de POA de tipo pesquero, se han vinculado con casos de intoxicaciones a los ostiones vaca (Spondylus calcifer) con toxinas de P. bahamense var. compressum. El cuadro clínico presentado correspondió a una intoxicación paralítica por mariscos mediada por saxitoxinas, y reporta que este metabolito tóxico es encontrado también en navajuelas (Tagelus spp) (Mata et al., 1990).

Con respecto a las ictiotoxicosis, sobresale el Síndrome Escombroide y ocurre por el consumo de peces con altos niveles de aminas biógenas (histamina) (Colombo et al., 2017), la cual se produce cuando las temperaturas de transporte o almacenamiendo de ciertas especies de peces es incorrecta y genera la descarboxilación de la histidina libre en los tejidos musculares. La producción de histamina ocurre por la degradación bacteriana, de la histidina (siendo Morganella morgani, Klebsiella pneumoniae y Hafnia alvei los microorganismos mayoritariamente implicados en el proceso), por lo que es un indicador de la poca higiene y mala manipulación del producto (Mahmoudi \& Mardani, 2015).

La liberación de subproductos como la histamina, los cuales incrementa su concentración en el tejido muscular de forma proporcional a la antigüedad del producto y a las altas temperaturas a las que este sea sometido. Las especies piscícolas que los producen son conocidas como histaminoproductores, por ejemplo: atún (Thunnus spp), dorado (Coryphaena hippurus), marlin (Makaira spp) y wahoo (Acanthocybium solandri). Como consecuencia se producen serias reacciones alérgicas en quienes consumen estos productos, pudiendo desencadenar en reacciones de hipersensibilidad tipo I (shock anafiláctico) e incluso la muerte.

La búsqueda bibliográfica no arrojó reportes de ictiotoxicosis en seres humanos o en POA en Costa Rica. Sin embargo, varias de las especies histamino-productores causantes de esta intoxicación antes mencionadas, se comercializan frecuentemente en el territorio costarricense, y la determinación de la concentración de histamina es un parámetro crítico (límite máximo permitido de $100 \mathrm{mg} / \mathrm{Kg}$ ) y de medición obligatoria dentro de la legislación sanitaria costarricense (Decreto Ejecutivo 34687-MAG, artículo 3.5).

Finalmente, es importante también mencionar las fitotoxinas, que son compuestos derivados de ciertas plantas. En el caso particular de Costa Rica, el más significativo lo constituye el Helecho Macho (Pteridium aquilinum), es una planta ubicua e invasiva que tiene un compuesto norsesquiterpeno (glucotoxina denominada ptaquilósido) que posee propiedades oncogénicas (alteración y modificación del ADN, desregulación de la expresión genética y de los mecanismos de señalización celular normalmente encontrados en los protooncogenes funcionales). La inducción de la apoptosis celular por inhibición de la proteína p53 es otro mecanismo fisiopatológico descrito (Herencia et al., 2013).

En consecuencia, se desarrolla la Hematuria Enzoótica Bovina (HEB) producto de la alteración y lesiones múltiples a nivel tanto del epitelio como de la vasculatura de la vejiga urinaria (Bulnes \& Tobar, 2014); así como también, sarcomas de la porción anterior del tracto digestivo de los animales afectados. Este compuesto carcinogénico puede ser excretado en leche, y lesiones similares pueden ser observadas en el ser humano cuando se ingiere este tipo de productos de origen animal con altos contenidos del ptaquilósido (Vetter, 2009).

Existen estudios a nivel de Costa Rica que han demostrado una correlación positiva entra las explotaciones bovinas con altas prevalencias de $P$. aquilinum, con la presencia de HEB y la 
distribución e incidencia de casos de cáncer gástrico en seres humanos en Costa Rica (Faz \& Tobar, 2012).

\section{Necesidad de implementar el enfoque UnaSalud en la gestión de las ETAs}

Los cambios en los sistemas de producción animal han ocurrido a pasos agigantados en las décadas recientes. Es posible distinguir 3 tipos de cambios prioritarios en el sector agroalimentario mundial (Reardon \& Timmer, 2014). A saber: 1) Transformación del sistema agroalimentario, 2) Conversión del mercado pecuario rural, y 3 ) Intensificación de la producción animal.

Es importante señalar que en su mayoría los brotes de ETAs son causados por microorganismos infecciosos. Estos organismos en algunos casos rompen la barrera entre especies y son capaces de migrar de los animales al hombre, por lo que constituyen en realidad zoonosis. Si la ruta de contagio involucra la ingesta del agente patógeno, entonces se está frente a una Zoonosis de Transmisión Alimentaria (ZTA). Algunas de ellas han aparecido en las últimas décadas, por lo que también pueden ser catalogadas como Zoonosis Emergentes (ZE).

En este sentido, la OMS define las ZE como aquellas enfermedades que han sido recientemente reconocida, un microorganismo conocido que ha logrado evolucionar hacia nuevos estados de patogenicidad y virulencia, ampliando su rango de especies afectadas o su rango geográfico (Asokan \& Asokan, 2016).

El aumento creciente en la demanda de productos y subproductos de origen animal (especialmente en países en desarrollo), ocasiona la expansión e intensificación de los sistemas productivos de índole pecuaria a una escala global. En consecuencia, ocurre un aumento concomitante en el volumen de bienes pecuarios y el movimiento de estos, haciendo que las fronteras comerciales sean cada vez más estrechas. Esto brinda mayores oportunidades para la transmisión y expansión amenazas a la bioseguridad en la forma de plagas y enfermedades a nuevos territorios, generando en ellos riesgos latentes en términos económicos, de salud pública y de sanidad animal.

Las pestes y las enfermedades animales generan una merma considerable en la productividad del sector agroalimentario (entre el 10-16\%), especialmente en países en vías de desarrollo (Campbell et al., 2016). Bajo esta línea de pensamiento, es pacífico afirmar que el aseguramiento de la sanidad animal, considerado un bien público mundial, es crucial para potencializar la productividad y rentabilidad de los sistemas agroproductivos actuales, pero también para el aseguramiento de la salud pública.

Es en las etapas iniciales de las cadenas de valor (producción primaria), que se requiere el empleo de un detallado análisis de riesgo, que permita evaluar la posibilidad de que un peligro determinado se presente en todos y cada uno de los eslabones que componen estos sistemas productivos (Lombardo et al., 2017). Lo anterior se debe, a que una gran cantidad de la carga de patógenos zoonóticos puede ser reducida en los alimentos, si se logra controlar su incidencia y prevalencia en el reservorio animal, por lo que es necesario mejorar los estándares productivos y controles sanitarios a nivel de la producción primaria.

Bajo esta misma línea de acción, la inversión en los sistemas de gestión de la sanidad animal es imperativa para poder asegurar la productividad eficiente e idónea de los insumos pecuarios (Chemineau, 2016). Esta inversión debe involucrar la mejora en capacitación e investigación de agentes de importancia en sanidad animal y salud pública. Una de las políticas pragmáticas para hacer frente a estos retos es el enfoque UnaSalud.

La iniciativa integradora de UnaSalud, es entendida como el enfoque cooperativo entre múltiples disciplinas para controlar y vencer las enfermedades emergentes y reemergentes en la interface entre hombre, animal y ecosistema (Dhama et al., 2013). Este planteamiento desde su inicio y origen está orientado a hacer frente a la emergencia de nuevos agentes nosógenos, los 
cuales poseen una interface dinámica y basada en sistemas. Esta relación entre animal (vertebrado o no), ser humano, ecosistemas y las variaciones antrópicas que alteran la nidalidad (dinámica ecológica) de los focos activos de infección, es la base fundamental del concepto.

Bajo esta premisa, es posible visualizar a los distintos tipos de encadenamientos agroproductivos como microbiomas megadiversos, dinámicos e influenciables por una o varias actividades antrópicas, que favorecen el tráfico microbiano y en donde los POA juegan un rol crucial en este proceso. En orden de poder controlar o minimizar los brotes por agentes patógenos incluidos aquellos causantes de ETAs, es necesario lograr identificar los factores que codifican para una mayor virulencia o resistencia, dilucidar las posibles rutas de infección, determinar los factores antrópicos que pueden permitir la infección en el ser humano, y desarrollar protocolos de monitoreo en producción primaria y en el producto terminado para disminuir la aparición de un peligro durante su proceso productivo y minimizar la severidad del mismo (Birhanu et al., 2015).

En este sentido, este enfoque muestra ser una herramienta sumamente práctica para la prevención, control, diagnóstico y mitigación del riesgo asociado a patógenos emergentes, incluidos algunos tipos de ETAs (Asokan \& Asokan, 2016). El concepto UnaSalud es un aspecto fundamental hoy en día, el cual mediante su implementación es esencial para la minimización de riesgos sanitarios en la interface humano-animal-ambiente. La lucha contra los microorganismos zoonóticos re-emergentes y emergentes, así como la resistencia antimicrobiana requiere de sistemas de salud plausibles y resilentes, junto a una coordinación efectiva entre los sistemas de salud pública, organismos veterinarios y el sector industrial.

Por tanto, el mayor reto en términos del concepto UnaSalud, consiste en lograr generar y desarrollar una colaboración intersectorial que permita su efectiva puesta en marcha para hacer frente a las amenazas emergentes. Ante este panorama, los Servicios Veterinarios (SV) de los países constituyen la primera línea de defensa, en la lucha contra las enfermedades zoonóticas reemergente y emergentes, mediante la ejecución de los estándares jurisprudenciales de la Organización Mundial de Salud Animal (OIE). De esta forma, los SV son agentes plausibles y esenciales de su funcionamiento, el monitoreo de tendencias de ETAs en diversas matrices alimentarias, el establecimiento de prioridades sobre su análisis de riesgo a lo largo de la agrocadena y la generación de incidencia política enfocada a controlar y comunicar los riesgos a los actores sociopolíticos de interés operativo (Wall 2014; Bonnaud \& Fortané, 2021).

En el campo de la higiene alimentaria, se busca concientizar a las autoridades locales de cada país para generar una red de tiempo real enfocada a comunicar incidentes relativos a la inocuidad de alimentos (Landford \& Nunn, 2012).

Por otra parte, en el concepto de gobernanza estatal es crucial para implementar el enfoque de integracionalidad multisectorial, necesaria para consensuar acciones coordinadas en torno a la inocuidad de los alimentos en el marco de la iniciativa UnaSalud. De esta forma, el enfoque UnaSalud, se convierte en una estrategia necesaria para hacer frente a la lucha contra las ETAs. Su aplicación correcta permite la transdisciplinariedad, el monitoreo sindrómico de los microorganismos y otros tipos de agentes de interés en materia de salud pública, así como también; la generación de bases de datos necesarias para la toma de decisiones en un sistema agroalimentario cada vez más complejo en donde la acción de la gestión sanitaria debe incluir un compromiso entre el sector estatal y productivo (Lee, 2017; García et al., 2020).

En aras de lograr operacionalizar el concepto UnaSalud en la cadena agroproductiva, es necesario contar primero con una adecuada coordinación y marco institucional que facilite su ejecución (Pouokam et al., 2017). De esta forma, las futuras intervenciones en salud deben ser realizadas desde un enfoque que permita una óptima integracionalidad dentro de un paradigma holístico y transdisciplinario (Kelly et al., 2014). 


\section{DISCUSIÓN}

La inocuidad alimentaria se define como: la condición o garantía de que un alimento no causará perjuicio al consumidor cuando éste sea preparado o ingerido de acuerdo con su uso previsto (Fonseca et al., 2015). La higiene de los insumos pecuarios, por tanto, no es sólo un aspecto inherente para la salvaguarda de la salud pública. Sino que constituye un elemento infraestructural crítico para asegurar la seguridad alimentaria y el derecho a la alimentación de la población.

Un elemento clave de la competitividad y acceso a mercados más rentables para los POA, y que incorpora expresamente la inocuidad de los mismos lo constituye la calidad de los alimentos. La calidad, por tanto, se constituye como una barrera comercial que exigen los consumidores, cada vez más conscientes, informados y atentos a los riesgos de los insumos alimentarios. Por otra parte, la globalización de mercados y el libre flujo de bienes, obliga a la instauración de estrategias para mitigar los riesgos a la inocuidad de los alimentos a través de las agrocadenas (Ortíz-Soto \& OrengoSerra, 2019).

La gobernanza de la inocuidad alimentaria es un proceso complejo y transversal, que abarca distintos niveles de marcos regulatorios y donde intervienen comúnmente diversas instituciones a distintas escalas espaciales. Esto es de gran importancia en el caso de Costa Rica, ya que la mayoría del conglomerado de empresas que componen el sector agroalimentario del país, son catalogados como pequeña y mediana industria (PYMES) (Cousin-Brenes, 2020). Se deben entonces, establecer marcos de trabajo cooperativo entre los productores locales de alimentos y los servicios regulatorios para que cada uno empatice sobre las necesidades y perspectivas del otro; siempre cumpliendo la normativa, permitiendo estructuras de agenciación y privatización efectiva, pero flexiblemente adaptables al entorno local.

En este sentido, las Enfermedades de Transmisión Alimentaria constituyen un impacto significativo en los sistemas de salud, producto de las personas que se enferman, incapacitan o mueren a causa de ellas, y por el gasto en la atención médica que las mismas ameritan. De los tres tipos de peligros existentes, los de tipo biológico son los que mayormente se asocian con brotes de ETAs, siendo esencialmente los microorganismos bacterianos los principales implicados (Varela et al., 2016).

La globalización de los mercados pecuarios ha tenido una expansión acelerada, creciendo en complejidad y en volumen comercializado. En los próximos años se espera un crecimiento poblacional significativo, y con ello una mayor demanda de productos de origen animal. Bajo este panorama, la emergencia y re-emergencia de patógenos alimentarios cobra relevancia (Nayak \& Waterson, 2019). Por ello, es necesario poder generar una integracionalidad de todos los actores de la agrocadenas, de forma que se permita la implementación del concepto UnaSalud en la legislación sanitaria de los países y en la gestión de las ETAs.

Los cambios provocados por el ser humanos en los sistemas agroalimentarios actuales, fomentan y catalizan hasta cierto punto, el tráfico microbiano. Es decir, el paso de un organismo de una especie a otra, y con ellos la emergencia de nuevos patógenos. Las ETAs no son la excepción a ello y los cambios que moldean la epidemiología de estos organismos, obedece esencialmente aspectos de índole social, sanitaria, productiva y ambiental (Lake \& Barker, 2018).

En este sentido, entre los factores sociales se puede mencionar el cambio en una dieta esencialmente basada en granos a otras con altos contenidos de proteína animal. En cuanto a los aspectos sanitarios se puede mencionar la globalización de los mercados que muchas veces permite la internacionalización de las enfermedades, y la ausencia de amalgamación de los sistemas de vigilancia y monitoreo epidemiológico humano-veterinario, algo de vital importancia en el caso de las ETAs en donde muchos de los organismos causales corresponden a zoonosis y otros menos, son antropozoonosis (García et al., 2020). 
En lo que respecta a los factores productivos, destacan la intensificación de los sistemas de producción y la generación de presión selectiva sobre microorganismos, que permite la migración de genes de resistencia o virulencia a través de distintas matrices alimentarias en las cadenas agroproductivas, y esto a su vez, predispone a la aparición de resistencias. Finalmente, la acción antrópica sobre los ecosistemas y el cambio climático, pueden generar condiciones como la eutrofización, que permiten el crecimiento de algunos organismos. Si los metabolitos de estos organismos pueden ser permeados en las distintas cadenas tróficas y ser humano, se constituye un problema palpable para los consumidores (García et al., 2020).

Entre los retos futuros para la salud pública e higiene alimentaria se puede citar: 1) fortalecimientos de los sistemas alimentarios sostenibles, especialmente en cuanto a la detección de patógenos causantes de ETAS, 2) detección temprana de patógenos emergentes, e 3) identificación de matrices y rutas de organismos resistentes a los antimicrobianos y mediados por productos de origen animal. Ante este panorama, la implementación de políticas públicas que sustenten la ejecución de acciones bajo el enfoque UnaSalud, son imperativos para establecer sistemas alimentarios funcionales y resilientes (Aiyar \& Pingali, 2020).

Una de las mayores dificultares para la puesta en práctica del enfoque UnaSalud, corresponde a su conceptualización y a las dificultades de lograr integrar distintas disciplinas (Ribeiro et al., 2019), muchas veces de diversos campos temáticos. En aras de facilitar proyectos de esta índole para el fortalecimiento de las políticas públicas de inocuidad alimentaria, se proponen las siguientes recomendaciones: 1) Fortalecimientos de los programas universitario en materia de inocuidad alimentaria, con especial énfasis a carreras con malla curricular en las áreas de ciencias de la salud y dando especial importancia al concepto UnaSalud, 2) Fortalecimiento de convenios público-privados, 3) Inclusión del sector académico dentro de los programas de monitoreo y vigilancia epidemiológica a través de la generación de observatorios locales en seguridad alimentaria y nutricional (SAN) dentro de los cuales la higiene alimentaria es vital, 4) Inclusión de patógenos emergentes dentro de la matriz de análisis que realizan los laboratorios certificados y estatales, 5) Establecimiento de programas de apoyo a las PYMES agroalimentarias para el fortalecimiento de sus sistemas de Gestión de Calidad (SGC), 6) Estandarización de esquemas de rastreabilidad y retiro de productos no conforme en las distintas agrocadenas destinadas a la producción, transformación, y comercialización de POA, 7) Programas de capacitación y promoción para la concientización a la sociedad civil y los tomadores sobre la importancia de implementar enfoque bajo el concepto UnaSalud como mecanismo preventivo para la prevención de distintos tipos de zoonosis; y 8) Gestión y desarrollo de programas de salud sostenibles en el tiempo (de carácter interdisciplinarios) que permitan determinar la migración y tipos de genes de resistencia y/o virulencia a través de las distintas matrices de POA.

\section{ÉTICA, CONFLICTO DE INTERESES Y DECLARACIÓN DE FINANCIAMIENTO}

Los autores declaran haber cumplido con todos los requisitos éticos y legales pertinentes, tanto durante el estudio como en el manuscrito; que no hay conflictos de interés de ningún tipo, y que todas las fuentes financieras se detallan plena y claramente en la sección de agradecimientos. Asimismo, está de acuerdo con la versión editada final del documento. El respectivo documento legal firmado se encuentra en los archivos de la revista. El porcentaje de contribución total para la conceptualización, preparación y corrección de este artículo fue A.C.R. 50\% y A.P.B 50\%. 


\section{REFERENCIAS}

Agger, M., Scheutz, F., Villumsen, S., Mølbak, K. \& Petersen, M. (2015). Antibiotic treatment of verocytotoxin-producing Escherichia coli (VTEC) infection: a systematic review and a proposal. Journal of Antimicrobial Chemotherapy, 70(9), 2440-2446. https://doi.org/10.1093/jac/dkv162

Aiyar, A. \& Pingali, P. (2020). Pandemics and food systems - towards a proactive food safety approach disease prevention \& management. Food Security, 12(4), 749-756. https://doi.org/10.1007/s12571-020-01074-3

Alvarado, M. \& Granados, F. (2015). Inocuidad microbiológica de los alimentos para animales en Costa Rica. Nutrición Animal Tropical, 9(3), 13-31. https://doi.org/10.15517/nat.v9i3.22280

Alvarado, V., Mora, M., Arias, M., Rojas, N. \& Chaves, C. (2011). Resistencia antimicrobiana de cepas de Staphylococcus aureus, Costa Rica. Revista Costarricense de Salud Pública, 20(2), $102-106$. https://www.scielo.sa.cr/pdf/rcsp/v20n2/art6v20n2.pdf

Álvarez, D., Jiménez-Díaz, M., \& Arias-Echandi, L. (2011). Estudio de la estabilidad microbiológica de la barracuda a través del tiempo de almacenaje en Costa Rica. Archivos Latinoamericanos de Nutrición, 61(2), 183-188.

Amalina, Z. \& Ina-Salwany, Y. (2016). Recent advancements in molecular detection of Vibrio species in aquatic animals: A review. Bioscience Biotechnology Research Communications, 9(3), 349-356. https://doi.org/10.21786/bbrc/9.3/3

Antillón, F., \& Rodríguez, E. (1992). Aislamiento de Vibrio cholerae no-01 en el Golfo de Nicoya, Costa Rica. Revista de Biología Tropical, 40(2), 231-232.

Araya, M., Davidovich, G., Chaves, C. \& Arias, L. (2005) Identificación de Enterococcus sp., en muestras de leche cruda del Área Metropolitana de Costa Rica y evaluación del patrón de sensibilidad a antibióticos. Archivos Latinoamericanos de Nutrición, 55(2), 161-166.

Araya-Fonseca, C., Boza-Cordero, R., Arguedas-Soto, L., Badilla-Baltodano, G. \& García-Santamaría, F. (2007). Infecciones nosocomiales por bacterias productoras de $ß$ lactamasa de espectro ampliado: prevalencia, factores de riesgo y análisis molecular. Acta Médica Costarricense, 49(2), 90-96. https://doi.org/10.51481/amc.v49i2.303

Arguedas, D; Dolz, G; Romero, J; Jiménez, E; León, D. (2010). Centrocestus formosanus (Opisthorchiida: Heterophyidae) como causa de muerte de alevines de tilapia gris Oreochromis niloticus (Perciforme: Cichlidae) en el Pacífico seco de Costa Rica. Revista de Biología Tropical, 58(4), 1453-1465. https://doi.org/10.15517/rbt.v58i4.5423

Arguedas, C., Ortega, S., Martínez, C. \& Astroza, C. (2017). Parasites of Nile Tilapia larvae Oreochromis niloticus (Pisces: Cichlidae) in concrete ponds in Guanacaste, Northern Costa Rica. Cuadernos de Investigación UNED, 9(2), 313 319. https://doi.org/10.22458/urj.v9i2.1904

Arias, L. \& Antillón, F. (2000). Contaminación microbiológica de los alimentos en Costa Rica. Una revisión de 10 años. Revista Biomédica, 11(2), 113-122. https://doi.org/10.32776/revbiomed.v11i2.226

Arias, L., Chaves, C. \& Solano, G. (2010). Evaluación de la prueba de reacción en cadena de la polimerasa (PCR) en la detección e identificación de Listeria monocytogenes en queso fresco proveniente del Área Metropolitana de San José, Costa Rica. Archivos Latinoamericanos de Nutrición, 60(4), 391-396.

Arias, L. \& Chaves, C. (2012). Calidad microbiológica de la materia prima y el producto final del ceviche de tilapia y de camarón expendidos en el Área Metropolitana de San José, Costa Rica. Cuadernos de Investigación UNED, 4(1), 85-92. https://doi.org/10.22458/urj.v4i1.136

Asokan, G. \& Asokan, V. (2016). Bradford Hill's criteria, emerging zoonoses, and One Health. Journal of Epidemiology and Global Health, 6(3), 125-129. http://dx.doi.org/10.1016/j.jegh.2015.10.002 
Bancerz-Kisiel, A. \& Szweda, W. (2015). Yersiniosis-a zoonotic foodborne disease of relevance to public health. Annals of Agricultural and Environmental Medicine, 22(3), 397-402. https://doi.org/10.5604/12321966.1167700

Barboza, K., Angulo, I., Zumbado, L., Redondo-Solano, M., Castro, E., \& Arias, M. (2017a). Isolation and Identification of Arcobacter Species from Costa Rican Poultry Production and Retail Sources. Journal of Food Protection, 80(5): 779-782. https://doi.org/10.4315/0362-028X.JFP-16-394

Barboza, K., Cubillo, Z., Castro, E., Redondo-Solano, M., Fernández-Jaramillo, H. \& Echandi, M. (2017b). First isolation report of Arcobacter cryaerophilus from a human diarrhea sample in Costa Rica. Revista do Instituto de Medicina Tropical de São Paulo, 59, e72. https://doi.org/10.1590/s1678-9946201759072

Blanco, W., Arias, M., Pérez, C., Rodríguez, C. \& Chaves, C. (2009). Detección de Bacillus cereus toxigénicos en productos lácteos con especias y leches deshidratadas. Archivos Latinoamericanos de Nutrición, 59(4), 402-406.

Birhanu, T., Mesfin, T. \& Eyasu. E. (2015). Review on Roles of Veterinary Services in Food Safety of Animal Origin in Ethiopia. Nature and Science, 13(6), 93-99.

Bogantes, V., Fallas-Padilla, L., Rodriguez-Rodriguez, E., Jaramillo, F. \& Echandi, L. (2015). Zoonotic species of the genus Arcobacter in poultry from different regions of Costa Rica. Journal of Food Protection, 78(4), 808-811. https://doi.org/10.4315/0362-028X.JFP-14-494

Bolaños-Acuña, M., Acuña-Calvo, T., Duarte-Martínez, F., Salazar-Castro, W., Oropeza-Barrios, G., Sánchez-Salazar, M. \& Campos-Chacón, E. (2007). Brotes de diarrea e intoxicaciones transmitidas por alimentos en Costa Rica, 2005. Acta Médica Costarricense, 49(4), 205-209. https://doi.org/10.51481/amc.v49i4.334

Bonnaud, L. \& Fortané, N. (2021). 21st century vets: professional dynamics in the era of OneHealth. Review of Agricultural, Food and Environmental Studies, 102, 121-124. https://doi.org/10.1007/s41130-021-00141-3

Brenes, R., Hangen, G., \& Duarte, G. (1984). Revisión de Paragonimus y paragonimiasis en Centroamérica y Panamá. Revista Médica del Hospital Nacional de Niños, Costa Rica, 19(2), 87-106.

Buehring, C., Shen, H., Jensen, M., Jin, D., Hudes, M., \& Block, G. (2015). Exposure to bovine leukemia virus is associated with breast cancer: a case-control study. PloS one, 10(9),e0134304. https://doi.org/10.1371/journal.pone.0134304

Buehring, G., Shen, H., Schwartz, A., \& Lawson, S. (2017). Bovine leukemia virus linked to breast cancer in Australian women and identified before breast cancer development. PloS one, 12(6), e0179367. https://doi.org/10.1371/journal.pone.0179367

Bulnes, C., \& Calderón Tobar, Á. (2014). Lesiones asociadas a la Hematuria Enzoótica Bovina (HEB) en animales de matadero (camal) de la Provincia Bolívar, Ecuador. Revista de Salud Animal, 36(2), 97-105.

Bustamante, W., Alpízar, A., Hernández, S., Pacheco, A., Vargas, N., Herrera, L. \& García, F. (2003). Predominance of vanA genotype among vancomycin-resistant Enterococcus isolates from poultry and swine in Costa Rica. Applied and Environmental Microbiology, 69(12), 7414-7419. https://doi.org/10.1128/AEM.69.12.7414-7419.2003

Carranza, F., Rivera, P., Chaves, C. \& Arias, L. (2013). Análisis bacteriológico del arroz con leche expendido en el área metropolitana de Costa Rica. Cuadernos de Investigación UNED, 5(2), 289-295. https://doi.org/10.22458/urj.v5i2.266

Calvo-Artavia, F. (2008). Modelo matemático para la estimación del riesgo de tuberculosis en carne bovina para consumo humano en tres mataderos de Costa Rica [Tesis de licenciatura, Universidad Nacional de Costa Rica]. https://repositorio.una.ac.cr/handle/11056/12888

Campbell, M., Vermeulen, J., Aggarwal, K., Corner-Dolloff, C., Girvetz, E., Loboguerrero, M., Ramírez-Villegas, J., Rosenstock, T., Sebastian, L., Thornton, P. \& Wollenberg, E. (2016). Reducing risks to food security from climate change. Global Food Security, 11, 34-43. https://doi.org/10.1016/j.gfs.2016.06.002. 
Carrique-Mas, J. \& Bryant, E. (2013). A review of foodborne bacterial and parasitic zoonoses in Vietnam. Ecohealth, 10(4), 465-489. 10.1007/s10393-013-0884-9

Chaabna, K. \& Alali, W. (2017). Enteric Salmonella in humans and food in the Middle East and North Africa: protocol of a systematic review. British Medical Journal Open, 7(7), e017399. http://dx.doi.org/10.1136/bmjopen-2017$\underline{017399}$

Chaves, D., Echeverry, A., Miller, F. \& Brashears, M. (2015). Prevalence of molecular markers for Salmonella and Shiga toxigenic Escherichia coli (STEC) in whole-muscle beef cuts sold at retail markets in Costa Rica. Food Control, 50, 497-501. https://doi.org/10.1016/j.foodcont.2014.09.024

Chaves, C., \& Arias, M. L. (2009). Caracterización de cepas de Listeria monocytogenes realizados a partir de queso fresco proveniente de diferentes zonas productoras costarricenses. Archivos Latinoamericanos de Nutrición, 59(1), 6670 .

Chemineau, P. (2016). Invited review: Importance of animal health and welfare for the stability of the three pillars of sustainability of livestock systems. Advances in Animal Biosciences, 7(2), 208-214. https://doi.org/10.1017/S2040470016000145

Choc, M., Jiménez, A., Arguedas, C. \& Dolz, G. (2020). Contracaecum multipapillatum (Nematoda: Anisakidae) en peces de aguas continentales de Guanacaste, Costa Rica e Izabal, Guatemala. Revista Colombiana de Ciencia Animal, 12(2), e767. https://doi.org/10.24188/recia.v12.n2.2020.767

Colello, R., Cáceres, E., Ruiz, J., Sanz, M., Etcheverría, I. \& Padola, L. (2016). From farm to table: follow-up of Shiga toxinproducing Escherichia coli throughout the pork production chain in Argentina. Frontiers in Microbiology, 7, 93. https://doi.org/10.3389/fmicb.2016.00093

Colombo, M., Cattaneo, P., Confalonieri, E. \& Bernardi, C. (2017). Histamine food poisonings: A systematic review and meta-analysis. Critical Reviews in Food Science and Nutrition, 58(7), 1131-1151. https://doi.org/10.1080/10408398.2016.1242476

Córdoba, M., Chaves, C., \& Arias, M. (2009). Identificación, cuantificación y determinación del perfil de sensibilidad a antibióticos de bacterias prebióticas adicionadas a productos de consumo frecuente en Costa Rica. Archivos Latinoamericanos de Nutrición, 59(2), 179-183.

Córdoba-Calderón, O., Redondo-Solano, M., Castro-Arias, E. \& Arias, L. (2017). Arcobacter isolation from minced beef samples in Costa Rica. Journal of Food Protection, 80(5), 775-778. https://doi.org/10.4315/0362-028X.JFP-16$\underline{493}$

Cortés., \& Madriz., M. (1987). Calidad microbiológica de almejas congeladas. Revista Costarricense de Ciencias Médicas, $8(1), 7-10$.

Cousin-Brenes, K. (2020). El surgimiento de las PYMES en Costa Rica desde una perspectiva histórica-económica (19502018). Revista de Ciencias Sociales, 169(3), 27-51. https://www.redalyc.org/articulo.oa?id=15365453003

Crump, A., Sjölund-Karlsson, M., Gordon, A. \& Parry, M. (2015). Epidemiology, clinical presentation, laboratory diagnosis, antimicrobial resistance, and antimicrobial management of invasive Salmonella infections. Clinical Microbiology Reviews, 28(4), 901-937. https://doi.org/10.1128/CMR.00002-15

Culquichicón, C., Hernández-Pacherres, A., Labán-Seminario, M., Cardona-Ospina, A. \& Rodríguez-Morales, J. (2017). Where are we after 60 years of paragonimiasis research? A bibliometric assessment. Le Infezioni in Medicina, 25(2), 142-149.

Cusick, D. \& Sayler, S. (2013). An overview on the marine neurotoxin, saxitoxin: genetics, molecular targets, methods of detection and ecological functions. Marine Drugs, 11(4), 991-1018. https://doi.org/10.3390/md11040991 
Decreto Ejecutivo 34687-MAG. (2008). RTCR 409: 2008 Reglamento de Límites Máximos Microbiológicos y de Residuos de Medicamentos y Contaminantes para los Productos y Subproductos de la Pesca y de la Acuicultura Destinados al Consumo Humano. Diario Oficial La Gaceta N¹60, 20 de agosto de 2008.

De la Cruz, E., Fournier, L., García, F., Molina, A., Chavarría, G., Alfaro, M., Ramírez, F. \& Rodríguez, C. (2014). Hazard prioritization and risk characterization of antibiotics in an irrigated Costa Rican region used for intensive crop, livestock and aquaculture farming. Journal of Environmental Biology, 35(1), 85-98.

Dhama, K., Chakraborty, S., Kapoor, S., Tiwari, R., Kumar, A., Deb, R., Rajagunalan, S., Singh, R., Vora, K. \& Natesan, S. (2013). One World, One Health. Veterinary Perspectives. Advances in Animal and Veterinary Sciences, 1(1), 5-13.

Díaz, J., \& Valerio, E. (2002). Diarrea por Vibrio parahaemolyticus: primer caso reportado en Costa Rica. Revista Médica del Hospital Nacional de Niños Dr. Carlos Sáenz Herrera, 37(1-2), 15-17.

Doucette, T. \& Tasker, A. (2008). Domoic Acid: detection methods, pharmacology and toxicology. En: Botana, L (Ed.). Seafood and Freshwater toxins: pharmacology, physiology, and detection (pp. 397-430). CRC Press. https://doi.org/10.1201/9781420007541.ch20

Farrokh, C., Jordan, K., Auvray, F., Glass, K., Oppegaard, H., Raynaud, S., Thevenot, D., Condron, R., De Reu, K., Govaris, A., Heggum, K., Heyndrickx, M., Hummerjohann, J., Lindsay, D., Miszczycha, S., Moussiegt, S., Verstraete, K. \& Cerf, O. (2013). Review of Shiga-toxin-producing Escherichia coli (STEC) and their significance in dairy production. International Journal of Food Microbiology, 162(2), 190-212. https://doi.org/10.1016/j.ijfoodmicro.2012.08.008

Faz, E. \& Tobar, A. (2012). Plantas tóxicas e inocuidad alimentaria: Hematuria Enzoótica Bovina por Pteridium spp. un problema relevante de salud. Revista de Salud Animal, 34(3), 137-143.

Fernández, T. (2002). Aislamiento y caracterización de cepas de Enterococcus vancomicina resistentes (VRE) en piezas de pollos de abastecimientos comerciales. [Tesis de licenciatura, Universidad de Costa Rica]. http://www.kerwa.ucr.ac.cr/handle/10669/16787?show=full

Fernández, D. (2014). Acerca de la nomenclatura científica en el caso particular de Salmonella. MediCiego, 20(Sup 2), 1-4.

Ferreira, V., Wiedmann, M., Teixeira, P. \& Stasiewicz, J. (2014). Listeria monocytogenes persistence in food-associated environments: epidemiology, strain characteristics, and implications for public health. Journal of Food Protection, 77(1), 150-170. https://doi.org/10.4315/0362-028X.JFP-13-150.

Fierro, A., Realpe, M., Meraz-Medina, T., Roman, S. \& Panduro, A. (2016). Hepatitis E virus: An ancient hidden enemy in Latin America. World Journal of Gastroenterology, 22(7), 2271. https://doi.org/10.3748/wjg.v22.i7.2271

Fischer, U. \& Weil, J. (2015). North American paragonimiasis: epidemiology and diagnostic strategies. Expert Review of Anti-infective Therapy, 13(6), 779-786. https://doi.org/10.1586/14787210.2015.1031745

Florin, I. \& Antillon, F. 1992. Production of enterotoxin and cytotoxin in Campylobacter jejuni strains isolated in Costa Rica. Journal of Medical Microbiology, 37(1), 22-29. https://doi.org/10.1099/00222615-37-1-22

Fonseca, A., Muñóz, A. \& Cleves, A. (2015). El sistema de gestión de calidad: elemento para la competitividad y la sostenibilidad de la producción agropecuaria colombiana. Revista de Investigación Agraria y Ambiental, 2(1), 922. https://doi.org/10.22490/21456453.909

Frasao, B., Marin, V. \& Conte-Junior, A. (2017). Molecular Detection, Typing, and Quantification of Campylobacter spp. in Foods of Animal Origin. Comprehensive Reviews in Food Science and Food Safety, 16(4), 721-734. https://doi.org/10.1111/1541-4337.12274

Freer, E. \& Vargas-Montero, M. (2003). Floraciones algales nocivas en la costa pacífica de Costa Rica: toxicología y sus efectos en el ecosistema y salud pública. Acta Médica Costarricense, 45(4): 158-164. https://doi.org/10.51481/amc.v45i4.120 
Gamboa-Coronado, M. D. M., Mau-Inchaustegui, S., \& Rodríguez-Cavallini, E. (2011). Caracterización molecular y resistencia antimicrobiana de aislamientos de Clostridium perfringens de diferentes orígenes en Costa Rica. Revista de Biología Tropical, 59(4), 1479-1485.

Garcia, N., Osburn, B. \& Jay-Russell, T. (2020). One health for food safety, food security, and sustainable food production. Frontiers in Sustainable Food Systems, 4, 1. https://doi.org/10.3389/fsufs.2020.00001

Granados-Chinchilla, F. (2017). A Focus on Aflatoxin in Feedstuffs: New Developments in Analysis and Detection, Feed Composition Affecting Toxin Contamination, and Interdisciplinary Approaches to Mitigate It. En: Lukman. B (Ed). Aflatoxin-Control, Analysis, Detection and Health Risks. (pp. 251-280). InTech. https://doi.org/10.5772/intechopen.69498

Grant, J. \& Booth, A. (2009). A typology of reviews: an analysis of 14 review types and associated methodologies. Health Information \& Libraries Journal, 26(2), 91-108. https://doi.org/10.1111/j.1471-1842.2009.00848.x

Gutiérrez, K., Alfaro, M., Granados, F., Sánchez, J., García, F. \& Rodríguez, C. (2010). Detección de tetraciclinas en nueve lotes de alimentos para cerdos, tilapias y pollos producidos en Costa Rica: incumplimiento de normativas y disconformidades con el etiquetado oficial de garantía. Agronomía Costarricense, 34(2), 145-151. https://doi.org/10.15517/rac.v34i2.3628

Herencia, K., Falcón, N., García, M., Chavera, A. \& Gonzáles, C. (2013). Prevalencia de hematuria vesical enzoótica bovina determinada mediante urianálisis en Oxapampa, Perú. Revista de Investigaciones Veterinarias del Perú, 24(1), 50-57. https://doi.org/10.15381/rivep.v24i1.1658

Herrera, L., Vargas, A., Moya, T., Campos, M. \& Yock, I. (2000). Aislamientos de Aeromonas hydrophila en el Hospital Nacional de Niños, 1995-1998. Revista Médica del Hospital Nacional de Niños Dr. Carlos Sáenz Herrera, 35(1-2), 73-77.

Hernández-Chea, R., Jiménez-Rocha, A., Castro, R, Blair, D. \& Dolz, G. (2016). Morphological and molecular characterization of the metacercaria of Paragonimus caliensis, as a separate species from P. mexicanus in Costa Rica. Parasitology International, 66(2), 126-133. https://doi.org/10.1016/i.parint.2016.12.006

Jaikel, T. \& Ramírez, D. (2010). Conocimientos y opiniones sobre la carne de pollo en dos comunidades rural-urbana de Costa Rica. Revista Costarricense de Salud Pública, 19(1), 3-11.

Janda, M., Abbott, L. \& Mclver, J. (2016). Plesiomonas shigelloides revisited. Clinical Microbiology Reviews, 29(2), 349-374. https://doi.org/10.1128/CMR.00103-15

Jami, M., Ghanbari, M., Zunabovic, M., Domig, J. \& Kneifel, W. (2014). Listeria monocytogenes in aquatic food products-a review. Comprehensive Reviews in Food Science and Food Safety, 13(5), 798-813. https://doi.org/10.1111/15414337.12092

Kadariya, J., Smith, C. \& Thapaliya, D. (2014). Staphylococcus aureus and staphylococcal food-borne disease: an ongoing challenge in public health. BioMed Research International, 827965. https://doi.org/10.1155/2014/827965

Kase, A., Correa, T., Luna, C., Sobsey, D. (2008). Isolation, detection and characterization of swine hepatitis E virus from herds in Costa Rica. International Journal of Environmental Health and Research, 18(3), 165-176. https://doi.org/10.1080/09603120701498311

Kopper, G., Calderón, G., Schneider, S., Domínguez, W., Gutiérrez, G., Rosell, C. \& Mejía, D. (2009). Enfermedades transmitidas por alimentos y su impacto socioeconómico. Informe de la Organización de las Naciones Unidas para la Agricultura y la Alimentación, 6, 1-194.

Kelly, A., Osburn, B. \& Salman, M. (2014). Veterinary medicine's increasing role in global health. The Lancet Global Health, 2(7), e379-e380. https://doi.org/10.1016/S2214-109X(14)70255-4

Lake, I. \& Barker, G. (2018). Climate change, foodborne pathogens, and illness in higher-income countries. Current Environmental Health Reports, 5(1), 187-196. https://doi.org/10.1007/s40572-018-0189-9 
Landford, J. \& Nunn, M. (2012). Good governance in 'One Health' approaches. Revue Scientifique et Technique de I'OIE, 31(2), 561-575. http://dx.doi.org/10.20506/rst.31.2.2133

Lazo, S. (2018). Determinación a perfiles de sensibilidad a antibióticos en bacterias del género Campylobacter spp., aisladas en pollo de engorde en tres puntos de la cadena avícola de Costa Rica. [Tesis de licenciatura, Universidad Nacional de Costa Rica]. https://repositorio.una.ac.cr/handle/11056/17223

Lee, B. (2017). Foodborne Disease and the Need for Greater Foodborne Disease Surveillance in the Caribbean. Veterinary Sciences, 4(3), 40. https://doi.org/10.3390/vetsci4030040

Leong, W., Anton, A., Rodrigues, F. \& Lie, W. (2016). Gene expression in the biosynthesis of paralytic shellfish poisoning (PSP) toxins in dinoflagellates: A mini review. Transactions on Science and Technology, 3(2), 374-381.

Lombardo, A., Boselli, C., Amatiste, S., Ninci, S., Frazzoli, C., Dragone, R., De Rossi, A., Grasso, G., Mantovani, A. \& Brajon, G. (2017). From invention to innovation: risk analysis to integrate One Health technology in the dairy farm. Frontiers in Public Health, 5, 302. https://doi.org/10.3389/fpubh.2017.00302

López, J. (2017). Inspección veterinaria en planta de proceso de bovinos. [Tesis de licenciatura, Universidad Nacional de Costa Rica]. https://repositorio.una.ac.cr/handle/11056/14414

MacRitchie, A., Hunter, J. \& Strachan, C. (2014). Consumer acceptability of interventions to reduce Campylobacter in the poultry food chain. Food Control, 35, 260-266. https://doi.org/10.1016/j.foodcont.2013.06.005

Madrigal, P., López, C., Arias, L., Salas, P. \& Chaves, C. (2013). Estudio bacteriológico de sushi preparado y comercializado en San José, Costa Rica. Revista Costarricense de Salud Pública, 22(1), 51-55.

Mahmoudi, R. \& Mardani, K. (2015). Histamines and foods: a review on importance, detection and controlling in foods. Malaysian Journal of Science, 34(1), 103-107. https://doi.org/10.22452/mjs.vol34no1.11

Manterola, C., Rojas, C., Totomoch-Serra, A., García-Méndez, N., \& Riffo-Campos, L. (2020). Genotipos de Echinococcus granulosus en hidatidosis humana alrededor del mundo. Revisión sistemática. Revista Chilena de Infectología, 37(5), 541-549. http://dx.doi.org/10.4067/S0716-10182020000500541

Marín, C., Fonseca, C., Arias, S., Villegas, I., García, A. \& Ishihara, H. (2009). Carga bacteriana de los peces Cynoscion squamipinnis (Perciformes: Scianidae) y Lutjanus gutattus (Perciformes: Lutjanidae) en la cadena de comercialización, Costa Rica. Revista de Biología Tropical, 57(1-2), 45-52. https://doi.org/10.15517/rbt.v57i12.11289

Martínez, M. \& Herrera, ML. (1997). Aislamiento de Escherichia coli O157: H7 a partir de heces de niños con síndrome urémico hemolítico. Revista Médica del Hospital Nacional de Niños Dr. Carlos Sáenz Herrera, 32(1-2), 5-8.

Mashouf, Y., Hosseini, M., Mousavi, M. \& Arabestani, R. (2015). Prevalence of enterotoxin genes and antibacterial susceptibility pattern of Staphylococcus aureus strains isolated from animal originated foods in West of Iran. Oman Medical Journal, 30(4): 283-290. https://doi.org/10.5001/omj.2015.56

Mata, L., Abarca, G., Marranghello, L. \& Víquez, R. (1990). Intoxicación paralítica por mariscos (IPM) por Spondylus calcifer contaminado con Pirodinium bahamense, Costa Rica, 1989-1990. Revista de Biología Tropical, 38(1), 129-136.

Molina, A., Chavarría, G., Alfaro-Cascante, M., Leiva, A. \& Granados-Chinchilla, F. (2019). Mycotoxins at the start of the food chain in Costa Rica: analysis of six Fusarium toxins and ochratoxin: A between 2013 and 2017 in animal feed and aflatoxin M1 in dairy products. Toxins, 11(6), 312. https://doi.org/10.3390/toxins11060312

Monge, R. \& Arias, M. (1991). Calidad microbiológica de alimentos vendidos en las fiestas populares. Revista Costarricense de Ciencias Médicas, 12(1,2): 17-24

Morabito, S., Silvestro, S. \& Faggio, C. (2017). How the marine biotoxins affect human health. Natural Product Research, 32(6), 621-631. https://doi.org/10.1080/14786419.2017.1329734 
Morales, G., Blanco, L., Arias, M. \& Chaves, C. (2004). Evaluación de la calidad bacteriológica de tilapia fresca (Oreochromis niloticus) proveniente de la Zona Norte de Costa Rica. Archivos Latinoamericanos de Nutrición, 54(4), 433-437.

Nayak, R., \& Waterson, P. (2019). Global food safety as a complex adaptive system: Key concepts and future prospects. Trends in Food Science \& Technology, 91, 409-425. https://doi.org/10.1016/i.tifs.2019.07.040

Odeyemi, A. \& Sani, A. (2016). Antibiotic resistance and burden of foodborne diseases in developing countries. Future Science, 2(4), FSO139. https://doi.org/10.4155/fsoa-2016-0023

Odeyemi, A. (2016). Public health implications of microbial food safety and foodborne diseases in developing countries. Food and Nutrition Research, 60, 29819. https://doi.org/10.3402/fnr.v60.29819

Olaya-Galán, N., Corredor-Figueroa, P., Guzmán-Garzón, C., Ríos-Hernandez, S., Salas-Cardenas, P., Patarroyo, A. \& Gutierrez, F. (2017). Bovine leukaemia virus DNA in fresh milk and raw beef for human consumption. Epidemiology \& Infection, 145(15), 3125-3130. https://doi.org/10.1017/S0950268817002229

Ortíz-Soto, M. \& Orengo-Serra, K. (2019). Factors considered from industry retailers and wholesalers in purchase intent for foreign products. Journal of Food Products Marketing, 25(5), 581-603. https://doi.org/10.1080/10454446.2019.1599309

Peck, W. \& van Vliet, H. (2016). Impact of Clostridium botulinum genomic diversity on food safety. Current Opinion in Food Science, 10, 52-59. https://doi.org/10.1016/i.cofs.2016.09.006

Peña, M. \& Nava, E. (2016). Sistema eco-amigable para procesos de sanidad alimentaria en industria de embutidos en México. Agronomía Colombiana, 34(Supl 1), S549-S552.

Pereira-Zamora, M. \& Wong-González, E. (2008). Sobrevivencia de Vibrio mimicus en la clara y en la yema del huevo de tortuga lora (Lepidochelys olivacea). Agronomía Mesoamericana, 19(2), 261-266. https://doi.org/10.15517/am.v19i2.5008

Pérez, E. (2015). Comparación del perfil toxigénico y presencia de mecA en aislamientos de Staphylococcus aureus provenientes de quesos y ambientes hospitalarios. [Tesis de licenciatura, Universidad de Costa Rica]. http://www.kerwa.ucr.ac.cr/handle/10669/30223

Pouokam, B., Foudjo, U., Samuel, C., Yamgai, F., Silapeux, K., Sando, T., Fankam, G. \& Frazzoli, C. (2017). Contaminants in Foods of Animal Origin in Cameroon: A One Health Vision for Risk Management "from Farm to Fork". Frontiers in Public Health, 5, 197, doi: 10.3389/fpubh.2017.00197. https://doi.org/10.3389/fpubh.2017.00197

Pulido-Murillo, A., Furtado, V., Melo, L., Rabelo, M. \& Pinto, A. (2018). Fishborne Zoonotic Trematodes Transmitted by Melanoides tuberculata Snails, Peru. Emerging Infectious Diseases, 24(3), 606-608. https://doi.org/10.3201/eid2403.172056

Quesada-Gómez, C., Mulvey, R., Vargas, P., del Mar Gamboa-Coronado, M., Rodríguez, C. \& Rodríguez-Cavillini, E. (2013). Isolation of a toxigenic and clinical genotype of Clostridium difficile in retail meats in Costa Rica. Journal of Food Protection, 76(2), 348-351. https://doi.org/10.4315/0362-028X.JFP-12-169

Reardon, T. \& Timmer, C. (2014). Five inter-linked transformations in the Asian agrifood economy: Food security implications. Global Food Security, 3(2), 108-117. https://doi.org/10.1016/i.gfs.2014.02.001

Reuben, A., Treminio, H., Arias, L. \& Chaves, C. (2003). Presence of Escherichia coli O157: H7, Listeria monocytogenes and Salmonella spp. in food from animal origin in Costa Rica. Archivos Latinoamericanos de Nutrición, 53(4), 389392.

Reyes-Lizano, L., Chinchilla-Carmona, M., Guerrero-Bermúdez, O., Arias-Echandi, L. \& Castro-Castillo, A. (2001). Trasmisión de Toxoplasma gondii en Costa Rica: Un concepto actualizado. Acta Médica Costarricense, 43(1), 36-38. https://doi.org/10.51481/amc.v43i1.48 
Ribeiro, S., van de Burgwal, H. \& Regeer, J. (2019). Overcoming challenges for designing and implementing the One Health approach: A systematic review of the literature. One Health, 7, 100085. https://doi.org/10.1016/j.onehlt.2019.100085

Rodríguez, E. \& Antillón, F. (1989). Aeromonas spp. y Plesiomonas shigelloides en bivalvos, cieno y aguas del Golfo de Nicoya, Costa Rica. Revista de Biologia Tropical, 37(1), 69-73

Rodríguez, J., Vargas, A. \& Herrera, L. (2000). Diarrea por Yersinia enterocolítica: Reporte de un caso. Revista Médica del Hospital Nacional de Niños Dr. Carlos Sáenz Herrera, 35(1-2), 79-82.

Rodríguez, F., Valverde, M., Zavaleta, E., Chaverri, J. (2008). Valoración de la prescripción de antibióticos en pacientes internados en la Unidad de Cuidados Intensivos de un Hospital Privado en Costa Rica diagnosticados con neumonía. Revista Médica de la Universidad de Costa Rica, 2(2), 1-12. https://doi.org/10.15517/rmu.v2i2.7847

Rodríguez-Ortíz, B., García-Prieto L. \& Pérez-Ponce de León, G. (2004). Checklist of the helminth parasites of vertebrates in Costa Rica. Revista de Biología Tropical, 52(2), 313-354. https://doi.org/10.15517/rbt.v52i2.15249

Rojas, X., Rojas, Y., Soto, L., Delgado, B. \& Hernández, F. (1996). Campylobacter sp. en pollos para consumo humano. Revista Costarricense de Ciencias Médicas, 17(1), 34-39.

Rojas, J., Rodríguez-Rodríguez, E., Pérez, C., Chaves, C. \& Arias, L. (2014). Presencia de los genes de toxigenicidad nheA, nheBy nheC en cepas de Bacillus cereus aisladas de leches deshidratadas en Costa Rica. Archivos Latinoamericanos de Nutrición, 64(3), 192-197.

Romero, J., Dávila, G., Beita, G. \& Dolz, G. (2015). Relación entre el estado serológico a leucosis bovina enzoótica y parámetros reproductivos en hatos lecheros especializados de Costa Rica. Agronomía Costarricense, 39(2), 7-18. https://doi.org/10.15517/rac.v39i2.21767

Salas-Vargas, V., Boza-Cordero, R., Bustamante-García, W., García-Santamaría, F. \& Barrantes-Valverde, E. (2004). Prevalencia e identificación genotípica de Enterococos Vancomicina resistentes en pacientes en un medio hospitalario. Acta Médica Costarricense, 46(1), 19-26. https://doi.org/10.51481/amc.v46i1.130

Serrano-Martínez, E., Quispe M., Hinostroza, E. \& Plasencia, L. (2017). Detección de parásitos en peces marinos destinados al consumo humano en Lima metropolitana. Revista de Investigaciones Veterinarias del Perú, 28(1), 160-168. https://doi.org/10.15381/rivep.v28i1.12935

Solano-Barquero, A. \& León-Alán, D. (2018). Parasitosis debidas a helmintos intestinales: una actualización sobre su abordaje y tratamiento farmacológico en Costa Rica. Revista del Colegio de Microbiólogos y Químicos Clínicos de Costa Rica, 24(1), 10-28.

Suarez-Isla, A. (2014). Saxitoxin and other paralytic toxins: toxicological profile. Marine and Freshwater Toxins: Marine and Freshwater. Toxins, 1-16. DOI 10.1007/978-94-007-6650-1_25-1

Tavares, B., Souza, A., Dulac, F., Moreira, M., Dominguez, L., Gonzalez, L., Cerecer, N. \& Timm, D. (2017). Contamination sources of Yersinia enterocolitica during milk production. Arquivo Brasileiro de Medicina Veterinária e Zootecnia, 69(2), 483-490. http://dx.doi.org/10.1590/1678-4162-8423

Thitaram, N., Frank, F., Siragusa, R., Bailey, S., Dargatz, A., Lombard, E., Haley, E., Lyon, A. \& Fedorka-Cray, J. (2016). Antimicrobial susceptibility of Clostridium difficile isolated from food animals on farms. International Journal of Food Microbiology, 227, 1-5. https://doi.org/10.1016/j.ijfoodmicro.2016.03.017

Tijerino, A., Bolaños, M., Acuña, T., Vargas, L. \& Chacón, C. (2016). Emergencia de $\beta$-lactamasa AmpC plasmídica del grupo CMY-2 en Shigella sonnei y Salmonella spp., en Costa Rica, 2003-2015. Revista Panamericana de Salud Pública, 40(1), 70-75.

Turner, D., Higgins, C., Davidson, K., Veszelovszki, A., Payne, D., Hungerford, J. \& Higman, W. (2015). Potential threats posed by new or emerging marine biotoxins in UK waters and examination of detection methodology used in their control: brevetoxins. Marine Drugs, 13(3), 1224-1254. https://doi.org/10.3390/md13031224 
Ulate, E., Rojas, G., Hernández-Chea, R., Jiménez-Rocha, A. \& Dolz, G. (2015). Diagnosis of human paragomiasis in Costa Rica using intradermal test and inmunoblot. Journal of Harmonized Research in Medical and Health Sciences, 2(3), 122-131.

Uyttendaele, M., De Boeck, E. \& Jacxsens, L. (2016). Challenges in food safety as part of food security: lessons learnt on food safety in a globalized world. Procedia Food Science, 6, 16-22. https://doi.org/10.1016/j.profoo.2016.02.003

Uzal, A., Freedman, C., Shrestha, A., Theoret, R., Garcia, J., Awad, M., Adams, V., Moore, R., Rood, J. \& McClane, A. (2014). Towards an understanding of the role of Clostridium perfringens toxins in human and animal disease. Future Microbiology, 9(3), 361-377. https://doi.org/10.2217/fmb.13.168

Van Asselt, D., Van der Fels-Klerx, J., Marvin, H., Van Bokhorst-van de Veen, H. \& Groot, N. (2017). Overview of food safety hazards in the European dairy supply chain. Comprehensive Reviews in Food Science and Food Safety, 16(1), 5975. https://doi.org/10.1111/1541-4337.12245

Varela, Z., Lavalle, L. \& Alvarado, D. (2016). Bacterias causantes de enfermedades transmitidas por alimentos: una mirada en Colombia. Revista de Salud Uninorte, 32(1), 105-122. https://doi.org/10.14482/sun.32.1.8598

Varela-Villalobos, R., Rojas-Granados, J., Valerio-Campos, I., \& Chinchilla-Carmona, M. (2013). Estado actual de la trasmisión de la toxoplasmosis por productos cárnicos en Costa Rica. Acta Médica Costarricense, 55(2), 82-86.

Vetter, J. (2009). A biological hazard of our age: bracken fern [Pteridium aquilinum (I.) kuhn] - a review. Acta Veterinaria Hungarica, 57(1), 183-196. http://dx.doi.org/10.1556/AVet.57.2009.1.18

Villagra-Blanco, R., Esquivel-Suárez, A., Wagner, H., Romero-Zúñiga, J., Taubert, A., Wehrend, A. \& Dolz, G. (2018). Seroprevalence and factors associated with Toxoplasma gondii, Neospora caninum and Coxiella burnetii infections in dairy goat flocks from Costa Rica. Veterinary Parasitology: Regional Studies and Reports, 14, 79-84. https://doi.org/10.1016/j.vprsr.2018.09.006

Villalobos, G., Jaramillo, F., Ulate, C. \& Echandi, L. (2013). Isolation and identification of zoonotic species of genus Arcobacter from chicken viscera obtained from retail distributors of the metropolitan area of San José, Costa Rica. Journal of Food Protection, 76(5), 879-882. https://doi.org/10.4315/0362-028X.JFP-12-400

Visciano, P., Schirone, M., Berti, M., Milandri, A., Tofalo, R. \& Suzzi, G. (2016). Marine biotoxins: occurrence, toxicity, regulatory limits and reference methods. Frontiers in Microbiology, 7:1051. https://doi.org/10.3389/fmicb.2016.01051

Wall, P. (2014). One Health and the food chain: maintaining safety in a globalised industry. Veterinary Record, 174(8), 189192. https://doi.org/10.1136/vr.g1512

Xiao, Y. \& Watson, M. (2019). Guidance on conducting a systematic literature review. Journal of Planning Education and Research, 39(1), 93-112. https://doi.org/10.1177/0739456X17723971

Ximenes, F., Gonçalves, B., Miyahira, C., Pinto, A., Melo, L. \& Santos, B. (2017). Centrocestus formosanus (Trematoda: Heterophyidae) in Melanoides tuberculata (Gastropoda: Thiaridae) from Vila do Abraão, Ilha Grande, Rio de Janeiro, Brazil. Brazilian Journal of Biology, 77(2), 318-322. http://dx.doi.org/10.1590/1519-6984.13615

Zumbado-Gutiérrez, L., Arévalo-Madrigal, A., Donado-Godoy, M. \& Romero-Zúñiga, J. (2014). Diagnóstico molecular de Campylobacter en la cadena avícola destinada para consumo humano en Costa Rica. Agronomía Mesoamericana, 25(2), 357-363. https://doi.org/10.15517/am.v25i2.15443

Zumbado-Gutiérrez, L., Romero, J., Barquero-Calvo, E., Gómes, J., Mora, M., Morovati, V. \& Arias, L. (2019). Frecuency and species of Campylobacter spp., in broiler at three levels of the poultry production chain of Costa Rica. International Journal of Current Research, 11(2), 1085-1089. DOI: https://doi.org/10.24941/ijcr.34091.02.2019 